\title{
Inspection of Used Fuel Dry Storage Casks
}

Dennis C. Kunerth

Tim McJunkin

Mark McKay

Sasan Bakhtiari

September 2012

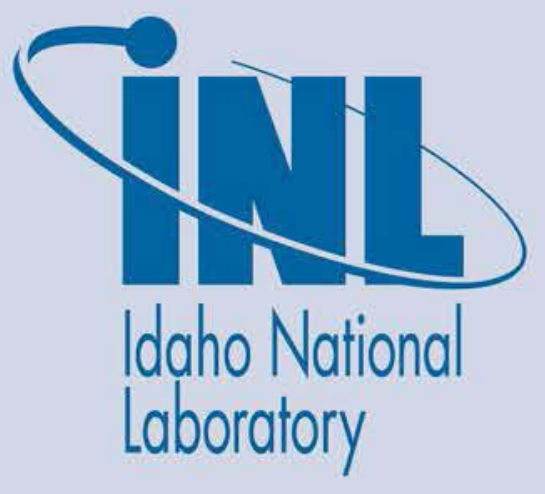

The INL is a U.S. Department of Energy National Laboratory operated by Battelle Energy Alliance 


\section{DISCLAIMER}

This information was prepared as an account of work sponsored by an agency of the U.S. Government. Neither the U.S. Government nor any agency thereof, nor any of their employees, makes any warranty, expressed or implied, or assumes any legal liability or responsibility for the accuracy, completeness, or usefulness, of any information, apparatus, product, or process disclosed, or represents that its use would not infringe privately owned rights. References herein to any specific commercial product, process, or service by trade name, trade mark, manufacturer, or otherwise, does not necessarily constitute or imply its endorsement, recommendation, or favoring by the U.S. Government or any agency thereof. The views and opinions of authors expressed herein do not necessarily state or reflect those of the U.S. Government or any agency thereof. 
INL/EXT-12-27119

FCRD-UFD-2012-000273

\section{Inspection of Used Fuel Dry Storage Casks}

Dennis C. Kunerth, Tim McJunkin, and Mark McKay (Idaho National Laboratory); Susan Bakhtiari (Argonne National Laboratory)

September 2012

Idaho National Laboratory

Materials Science and Engineering

Idaho Falls, Idaho 83415

http://www.inl.gov

Prepared for the

U.S. Department of Energy

Office of Nuclear Energy

Under DOE Idaho Operations Office

Contract DE-AC07-05ID14517 

Materials Science and Engineering

Inspection of Used Fuel Dry Storage Casks

INL/EXT-12-27119

FCRD-UFD-2012-000273

September 2012

Approved by:

Dennis C. Kunerth

Dennis C. Kunerth

Author

$08 / 30 / 2012$

SMBuk

$8 \cdot 30 \cdot 12$

Sandra M. Berk

Department Manager, Nuclear Materials Disposition \&

Date

Engineering 



\begin{abstract}
The U.S. Nuclear Regulatory Commission (NRC) regulates the storage of used nuclear fuel, which is now and will be increasingly placed in dry storage systems. Since a final disposition pathway is not defined, the fuel is expected to be maintained in dry storage well beyond the time frame originally intended. Due to knowledge gaps regarding the viability of current dry storage systems for long term use, efforts are underway to acquire the technical knowledge and tools required to understand the issues and verify the integrity of the dry storage system components. This report summarizes the initial efforts performed by researchers at Idaho National Laboratory and Argonne National Laboratory to identify and evaluate approaches to in-situ inspection of dry storage casks. This task is complicated by the design of the current storage systems that severely restrict access to the casks.
\end{abstract}




\section{CONTENTS}

ABSTRACT $\mathrm{V}$

ACRONYMS

Error! Bookmark not defined.

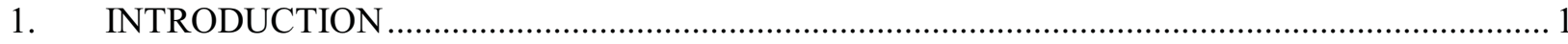

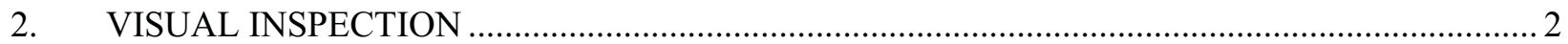

3. SURFACE/VOLUMETRIC NONDESTRUCTIVE EVALUATION ........................................ 4

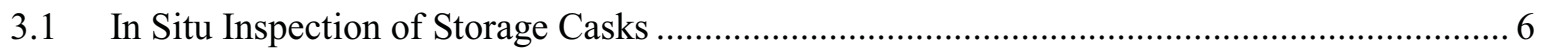

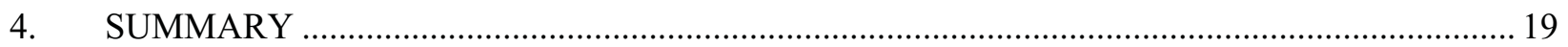

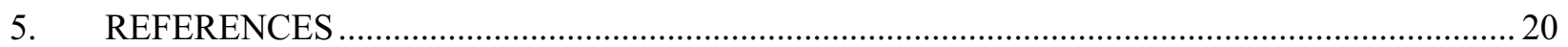

\section{FIGURES}

Figure 1. One configuration used for the dry storage of used nuclear fuel. (Image from U.S. NRC website http://www.nrc.gov/reading-rm/doc-collections/fact-sheets/dry-cask-

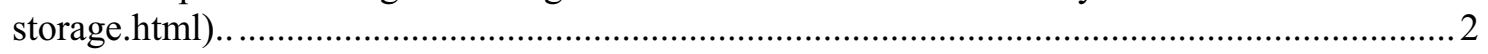

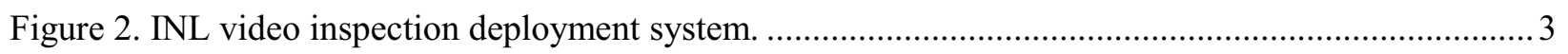

Figure 3. Simulated positioning of INL video inspection deployment system......................................... 3

Figure 4. Eddy current C-scan of transverse and axial notches in an Alloy 22 calibration block. ............... 4

Figure 5. Simulated electronic scanning results for a 64 element two-dimensional array with 2.5

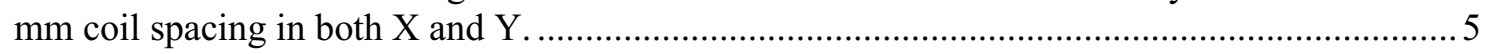

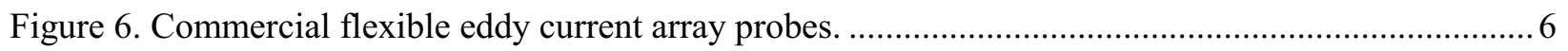

Figure 7. Array probe with 32 axial and 30 transverse elements. Shown here are the (left) top and bottom view of the probe head and (right) T-R coil configuration............................................

Figure 8. (a) Sonaspection plate with transverse weld cracks and tabulated data providing a list of flaws present in the sample, and (b) typical scanning setup for inspection of samples............... 8

Figure 9. Eddy current inspection data collected at INL from Sonaspection plate containing 3-toe cracks: (a) shows data displayed over a small section of the sample using the commercial software and (b) shows processed data using the ANL data analysis software with the location of flaws marked by circles and arrows.

Figure 10. Eddy current inspection data collected at INL from Sonaspection plate containing 3toe cracks shown in Figure 9(a). Data at various stages of processing are displayed using the ANL data analysis software with the location of flaws marked by circles and arrows.

Figure 11. Simulated eddy current T-R probe response to a 12-mm long, 1-mm deep surface breaking crack in a type 304 SS plate as a function of probe position. Figure (a) shows impedance plane trajectories for six transverse scans to flaw axis (middle of crack at 0 $\mathrm{mm}$ ), Figure (b) shows magnitude plot ( $|\mathrm{Z}|$ ) along transverse direction, and Figure (c) shows terrain plots generated from raster scan data. 
Figure 12. Simulated eddy current T-R probe response to a 12-mm long surface breaking cracks ranging from $0.25 \mathrm{~mm}$ to $3 \mathrm{~mm}$ deep in a type $304 \mathrm{SS}$ plate. Figure (a) shows impedance plane trajectories for five transverse scans to flaw axis along the line crossing the middle of the crack and Figure (b) shows magnitude plot $(|\mathrm{Z}|)$ along transverse direction as a function of position.

Figure 13. Simulated eddy current T-R probe response to a $12-\mathrm{mm}$ long surface breaking crack in a type $304 \mathrm{SS}$ plate for three different coil spacing/gaps ranging from 0.5 to $2 \mathrm{~mm}$. Figure (a) shows impedance plane trajectories for transverse scans to flaw axis along the line crossing the middle of the crack and Figure (b) shows magnitude plot $(|\mathrm{Z}|)$ along transverse direction as a function of position.

Figure 14. Simulated eddy current T-R probe response to a 12-mm long surface breaking crack in a type $304 \mathrm{SS}$ plate for four different coil diameters ranging from 1.5 to $4 \mathrm{~mm}$. Figure (a) shows impedance plane trajectories for transverse scans to flaw axis along the line crossing the middle of the crack and Figure (b) shows magnitude plot (|Z|) along transverse direction as a function of position.

Figure 15. Two methods of scanning material: (left) an articulated positioning system for scanning a canister, (right) the electronic scanning and focusing available through phased array ultrasonics

Figure 16. Combining mechanical scanning with phased array scanning and focusing produces a detailed view of the material defects as shown in the UT volumetric data shown with the cross-sections of the weld that was scanned.

Figure 17. Auto focusing and analysis of the focal delays allows the determination of the exact physical location of the reflection. The amplitude over the period of focusing is shown in the center along with the expected location of Shear and Longitudinal wave fronts. Convergence of the L-wave on the bottom right establishes the location of a reflection with respect to the transducer. 


\section{Inspection of Used Fuel Dry Storage Casks}

\section{INTRODUCTION}

The U.S. Nuclear Regulatory Commission (NRC) regulates the storage of used nuclear fuel, which is now and will be increasingly placed in dry storage systems. Since a final disposition pathway is not defined, the fuel is expected to be maintained in dry storage well beyond the time frame originally intended. As a result, a gap in knowledge exists regarding the long term integrity of the storage systems and stored fuel. Efforts are presently underway through the U.S. Department of Energy Office of Nuclear Energy Used Nuclear Fuel Disposition Program to identify the knowledge gaps and the path forward to assure safe storage and subsequent transportation of the spent nuclear fuel. ${ }^{1-3}$ As part of this effort, various possible degradation mechanisms have been identified, including atmospheric and aqueous corrosion of the welded and bolted casks, which includes the onset of stress corrosion cracking for 300 series stainless steel structures near marine environments. The Idaho National Laboratory (INL) is presently evaluating approaches to detect and characterize the presence of this type of degradation for casks now in dry storage.

As part of the NRC relicensing process for dry storage systems, NUREG-1927 provides guidance to perform visual examination of one or more lead canisters, its support structure, and internals of the concrete overpack to demonstrate that no unanticipated degradation has occurred. It does not specify what should be done if, based on some criteria, suspect regions are identified. Various nondestructive evaluation (NDE) inspection technologies can potentially characterize suspect regions with respect to the presence and extent of material degradation. However, applying these technologies will present significant challenges because of the environment and the limited access within the storage system.

The test environment includes elevated levels of ionizing radiation and test surfaces with elevated temperatures and possible accumulations of debris. The most significant hurdle will be access to the structures or components that need to be inspected. The radiation hazard results in regulatory and economic issues that impede removal of the casks for easy access and prevent direct contact by humans. This imposes the need for remote inspection within the storage system using robotic approaches to place and/or scan inspection devices over surfaces of interest. The robotic systems required will need to have extended reach and fit through narrow or labyrinth openings. This will limit sensor payload and capabilities. A typical configuration used for the dry storage of used nuclear fuel is presented in Figure 1. 


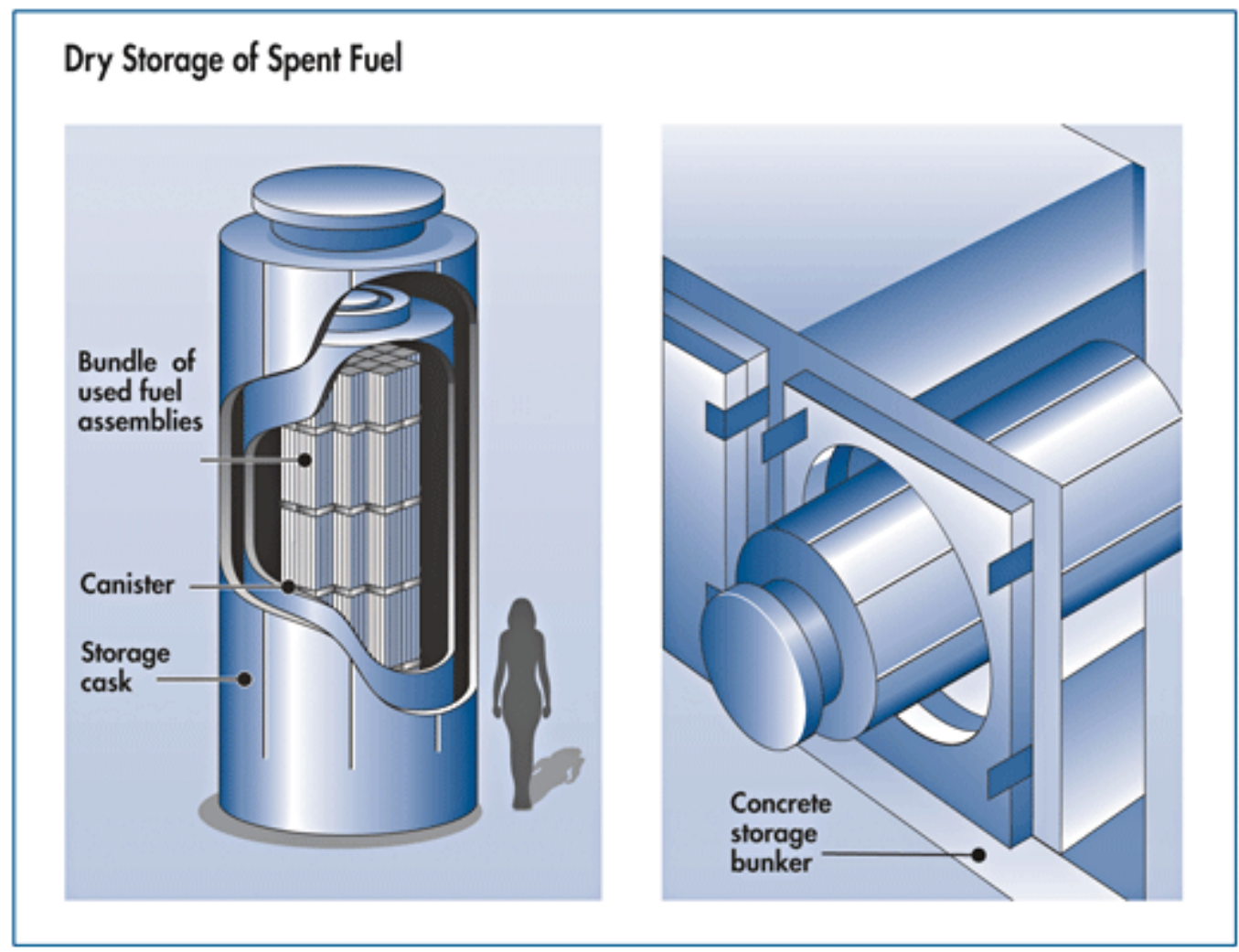

Figure 1. One configuration used for the dry storage of used nuclear fuel. (Image from U.S. NRC website http://www.nrc.gov/reading-rm/doc-collections/fact-sheets/dry-cask-storage.html).

\section{VISUAL INSPECTION}

Researchers in the robotics group are presently developing and testing a robotic video deployment system designed to increase reach and flexibility for inspections performed within the concrete overpack. The system is designed with three joints to permit greater flexibility in reaching around the cask and support structures as shown in Figures 2 and 3. The deployment system is designed to initially position a flexible video bore scope camera housed internal to the jointed structure. Bore scopes can also have a steerable articulated tip to providing additional viewing capabilities once positioned by the deployment system. Typically bore scope inspection systems provide illumination as well as optical examination and image capture/recording capabilities suitable for image processing and evaluation. 


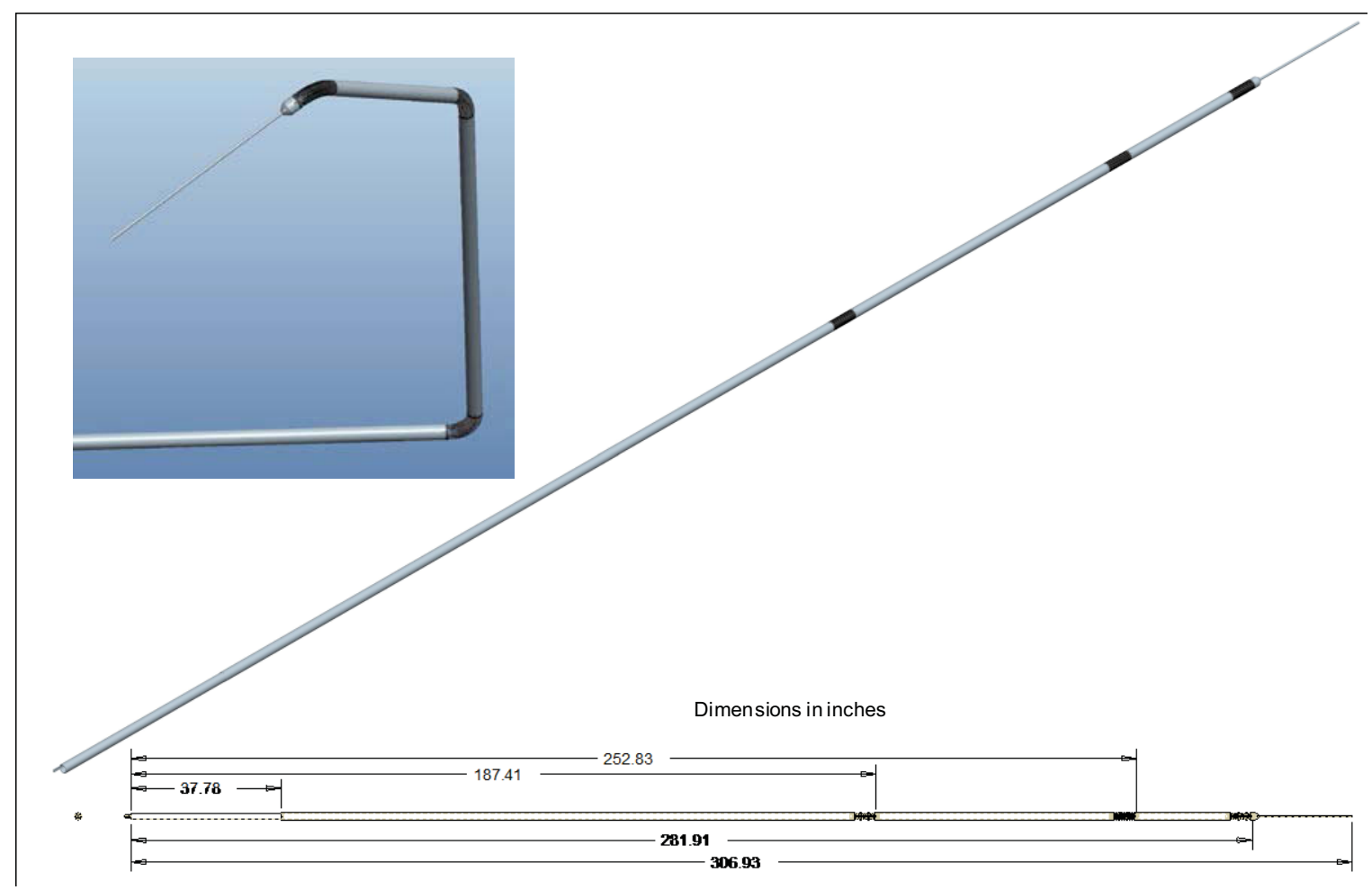

Figure 2. INL video inspection deployment system.
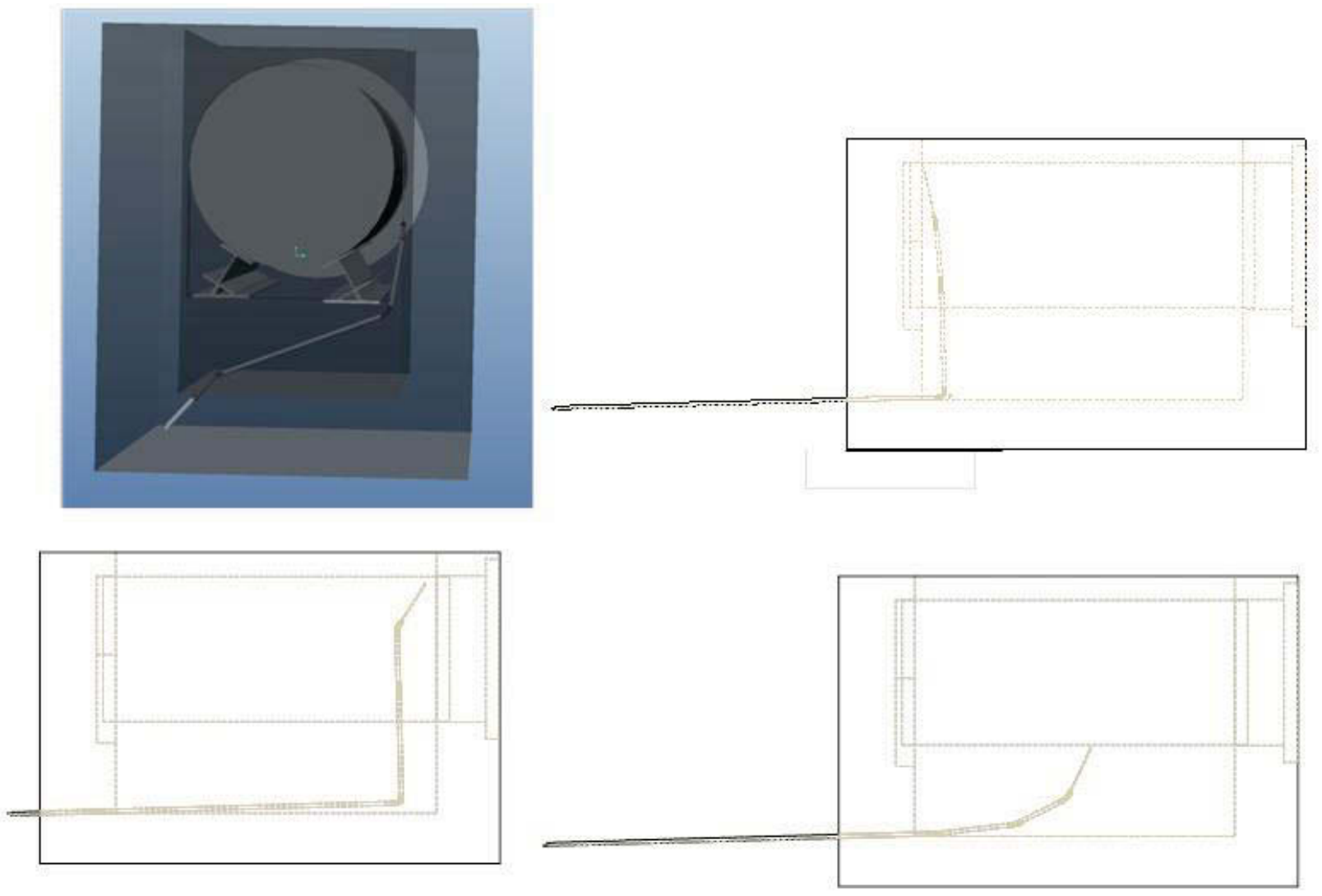

Figure 3. Simulated positioning of INL video inspection deployment system. 


\section{SURFACE/VOLUMETRIC NONDESTRUCTIVE EVALUATION}

Other inspection technologies that can potentially be remotely deployed for inspection of casks and support structures include eddy currents (a surface/near surface inspection technique) and ultrasonics (a volumetric inspection technique). Eddy current testing (ET) is a well established inspection technology capable of inspecting metallic components for surface defects or near-surface defects within the skin depth of the sample as determined by the test parameters. One skin depth is defined as the depth within the test sample where the eddy current field drops to 1/e of the value measured at the surface of the test sample (approximately 37\%). Skin depth is determined by the combination of the test materials' electrical conductivity and magnetic permeability and the test frequency. A low conductivity material with a relative magnetic permeability of 1 , such as a 300 series stainless steel, combined with a low test frequency permits several millimeters of eddy current penetration.

ET is based on generating eddy currents in an electrically conductive test sample through inductive coupling with a test coil. The primary electromagnetic properties of interest are electrical conductivity and magnetic permeability and any material or physical condition (e.g., cracks, changes in grain structure or different phases) that locally affects these properties can be detected and characterized. Material anomalies are typically sensed through changes in the test coil impedance but can also be sensed via direct magnetic field measurements.

The classical approach is to scan a single or array transducers over the surface of interest as shown in Figure 4. The notches in Figure 4 are $0.13 \mathrm{~mm}$ wide by $0.26 \mathrm{~mm}$ deep and the notch lengths are 1.3, 1.6, and $2.3 \mathrm{~mm}$. A 64 element transmit-receive array was used that simultaneously collects transverse and axial C-scans. The array elements are $2 \mathrm{~mm}$ diameter coils with a center-to-center separation of $2.5 \mathrm{~mm}$. The coils are arranged in four staggered rows of 16, providing an element pitch of $1.25 \mathrm{~mm}$. Because of limited access and limited payload of robotic delivery systems, the mechanical scanning used to collect the data in Figure 4, may be impractical.

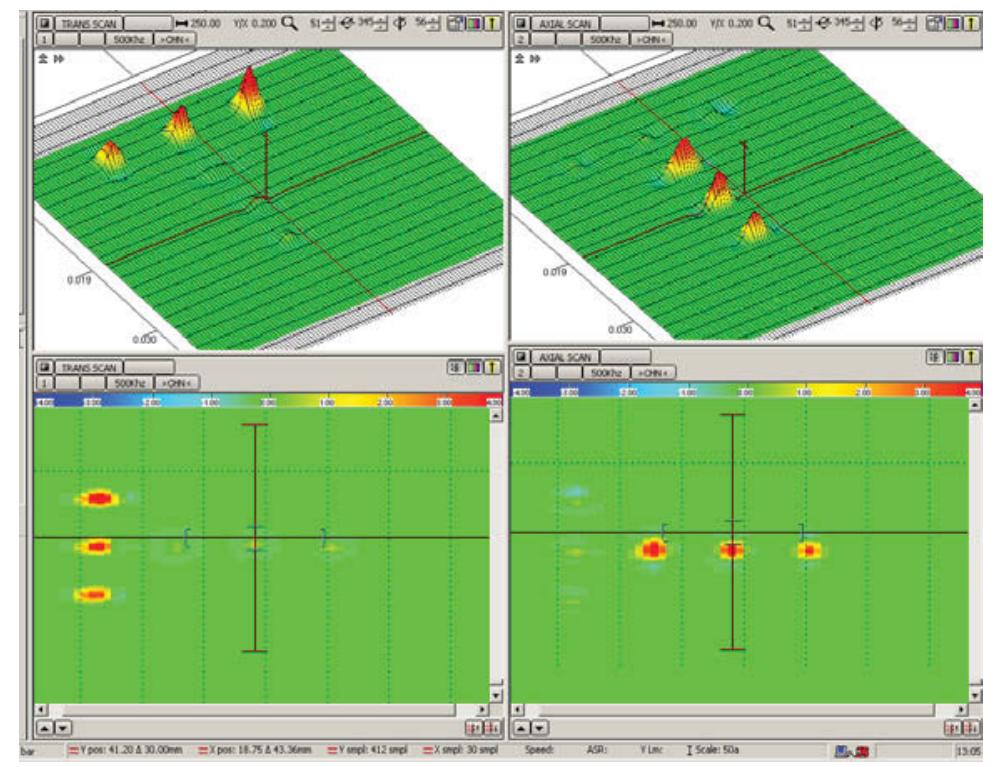

Eddy CurrentArray Probe

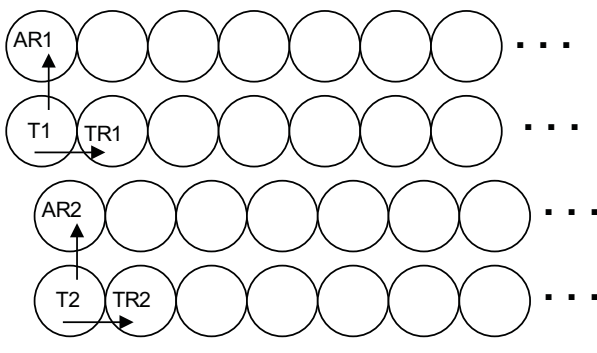

4 rows of 16 Elements

( $2 \mathrm{~mm}$ Pancake Coils Separated by $2.5 \mathrm{~mm}$ )

Figure 4. Eddy current C-scan of transverse and axial notches in an Alloy 22 calibration block. 
Another approach is to design and build two-dimensional (2-D) arrays that can be scanned electronically. Using this approach, the deployment system only has to position and hold down the probe at the test location. This is illustrated in Figure 5 where a single, $6 \mathrm{~mm}$ absolute coil was incrementally scanned over a $40 \times 10 \mathrm{~mm}$ area using $2.5 \mathrm{~mm}$ steps to simulate electronic scanning of a 2-D array. This provides a similar coil arrangement to the 64 element transmit-receive probe used to collect the data presented in Figure 4. The amplitude of the real component is plotted. Note that the three axial electrodischarged machined (EDM) notches are obvious but the center transverse notch is not. This may be due to the coarse spatial resolution employed for this illustration. The outer transverse notches were not in the scan region. Because of the coil and step sizes used, the image has relatively coarse spatial resolution but still has the capability to detect the EDM notches. EDM notches are typically used to as a convenient means to simulate cracking in metals. Smaller coil sizes and spacing can be used to improve spatial resolution and defect detection capabilities.

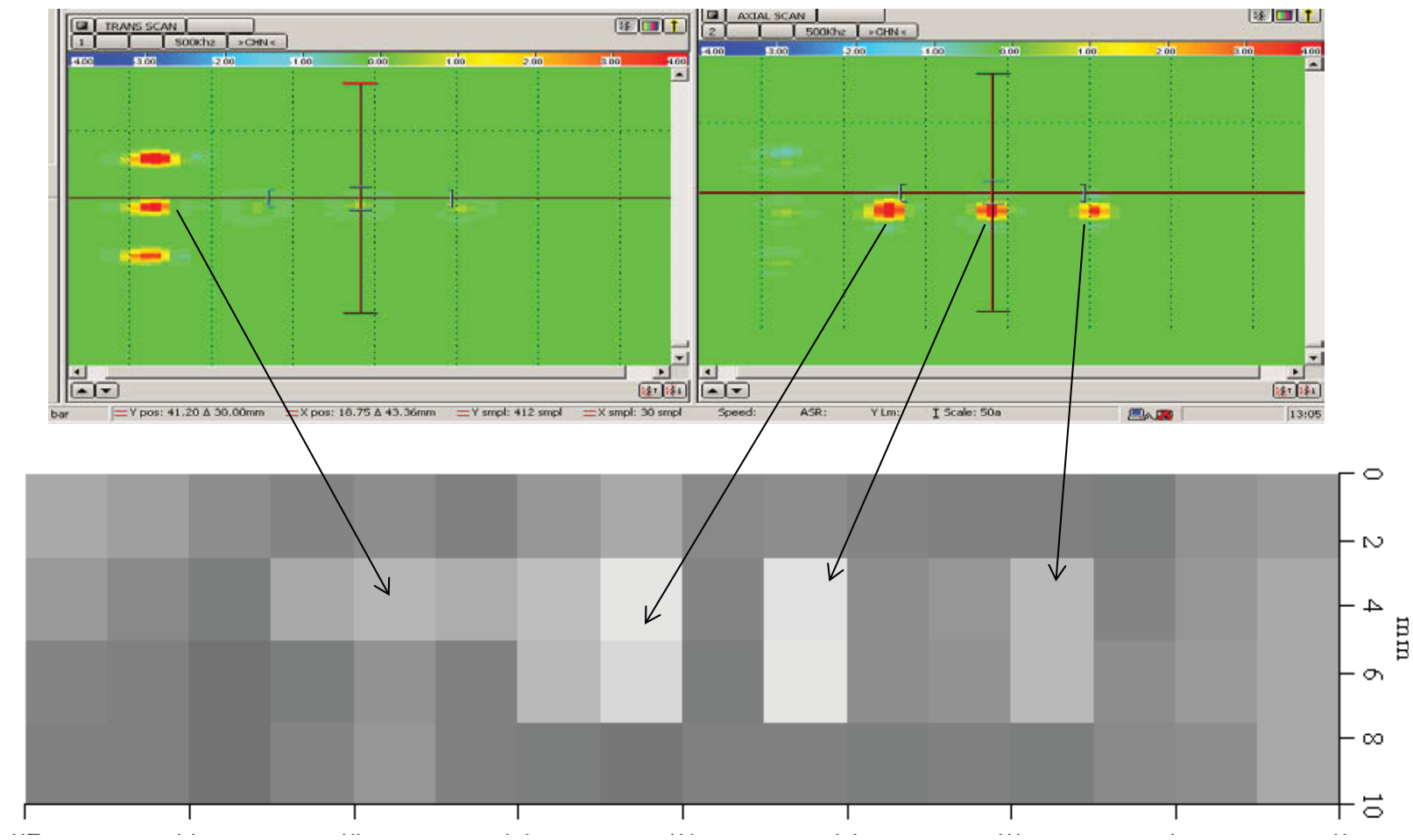

Figure 5. Simulated electronic scanning results for a 64 element two-dimensional array with $2.5 \mathrm{~mm}$ coil spacing in both $\mathrm{X}$ and $\mathrm{Y}$.

Eddy current vendors presently have array technologies that meet the spirit of this approach. For example, EddyFi Inc. and Olympus NDT Inc. have eddy current array instrumentation and thin flexible array probes designed for mechanical scanning as shown in Figure 6. Redesigning these types of probes for electronic scanning, i.e., to optimize coverage and spatial resolution, and fabricating them with heat tolerant materials forms the basis of a light-weight eddy current sensor that can be integrated with a robotic deployment system. Associated with this will be the need to improve data analysis capabilities to permit characterization of the detected anomalies. 


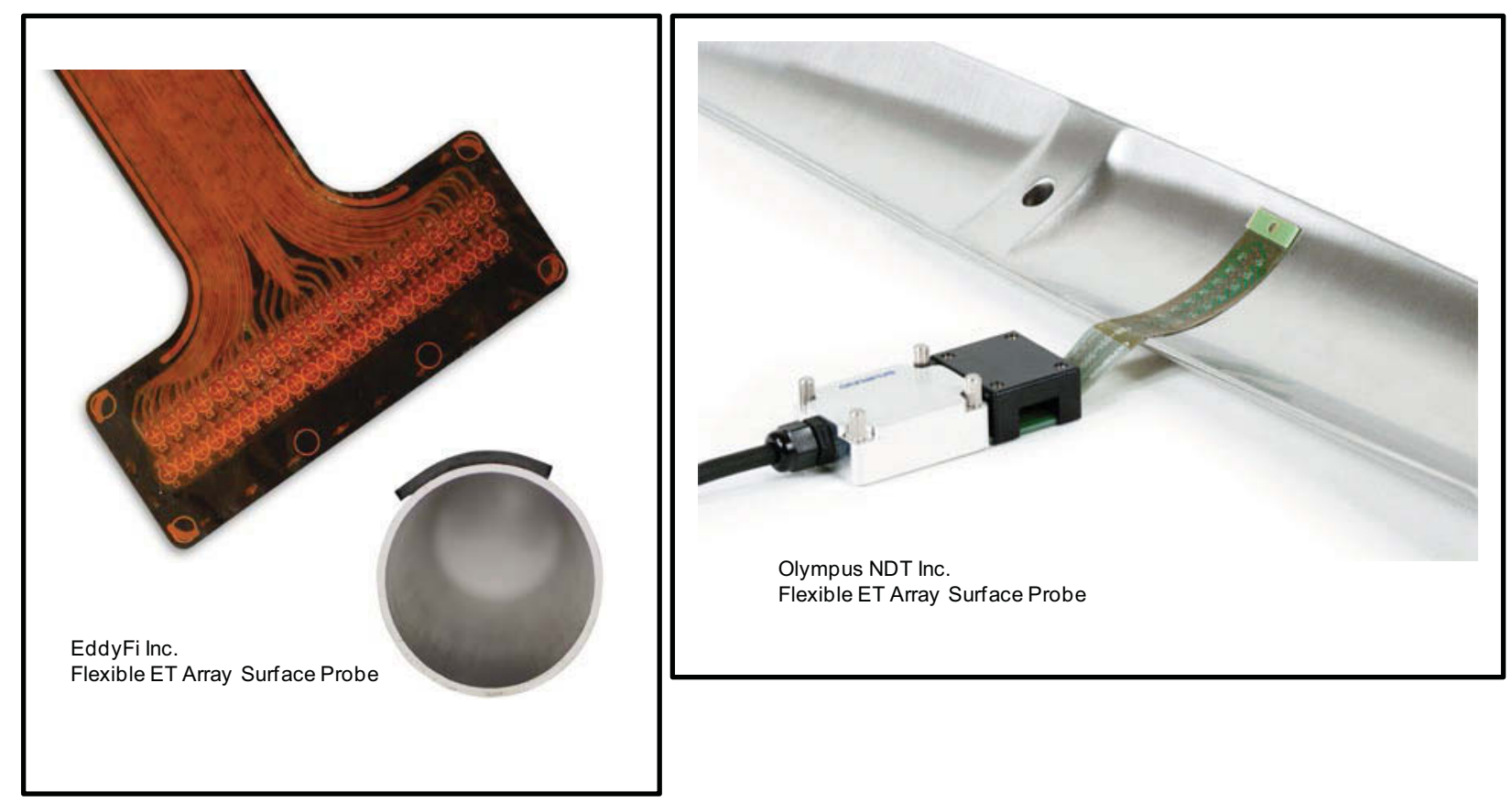

Figure 6. Commercial flexible eddy current array probes.

INL and Argonne National Laboratory (ANL) are collaborating to improve the capabilities of eddy current inspection methods for in situ NDE inspection of used fuel dry storage casks. An advanced ET method based on array probe technology is being evaluated in this work for examination of both welded and bolted cask designs. Experimental efforts thus far have focused on the evaluation of surfaceconforming array probes for the more challenging problem of weld inspection. An array probe with driver-pickup elements available at INL is being evaluated for this purpose. A number of calibration standard samples are currently being used in these investigations. In parallel, theoretical simulations are being conducted to help optimize the probe design. The analytical and numerical studies are aimed at optimizing the array probe design by increasing the probe coverage with acceptable losses in sensitivity and spatial resolution for detection of limiting flaws. The optimized probe design is expected to eliminate the need for continuous scanning of the probe in tight spaces. Finally, advanced signal processing and data analysis algorithms developed earlier at ANL are being adapted to the processing of NDE data from storage casks. Such tools are expected to help improve detection and characterization of potential flaws in storage cask components and to further help automate the inspection process.

\subsection{In Situ Inspection of Storage Casks}

Reliable detection of defects and degradations at welded regions of the metallic cask is a potential concern to long-term structural integrity. The presence of residual stresses at metal welds, exposure to corrosive environments, and the quality of the workmanship renders the welded regions of the cask prone to a number of manufacturing defects and degradation modes, including stress corrosion cracking. Inservice inspection of metal casks using conventional NDE techniques is a challenging task. The difficulty is associated primarily with the lack of access to the cask surface. In a number of storage cask designs a small gap/annulus separates the canister from the external shielding structure (e.g., concrete over-pack). The problem is further exacerbated as the inspection may have to be performed through small openings (air inlet and outlet). Eddy current testing in its various forms is among the most prominent techniques used for inspection of electrically conducting materials and has been demonstrated to reliably detect surface and near-surface flaws in metallic structures. The confined space of the storage systems, however, limits the use of conventional ET techniques that commonly require mechanical scanning of a probe over 
the test piece. High-resolution ET array probes have been identified as a promising NDE method for insitu inspection. This is because array probe technology allows measurements to be made more efficiently over large areas, thus minimizing the need for elaborate scanning systems.

As one of the tasks under this program, the applicability of ET array probe technology for in situ NDE of casks is currently being evaluated. Both ANL and INL are involved in this collaborative effort. The work involves:

1. Experimental evaluation of existing ET array probes

2. Optimization of probe design using numerical electromagnetic modeling

3. Development of modern signal processing and data analysis tools for automatic processing of data.

A series of tests have been conducted to assess the ability of array probes to detect and characterize flaws in welded regions. The experimental efforts so far have been limited to the inspection of calibration samples that resemble the type of welds used for manufacturing canisters. Figure 7 displays an eddy current array probe used at INL to examine the samples. The probe head houses 32 axial and 30 transverse probes. The probes operate in driver-pickup/transmit-receive (T-R) mode and may be excited over a wide range of frequencies. The surface conforming design of the array probe allows scanning of contoured surfaces while minimizing the probe lift-off effects. The samples were all scanned with the probe mounted on a computer controlled two-axis translation stage. Data acquisition at INL was performed using a commercially available eddy current instrument and the associated software. Figure 8(a) displays a representative calibration standard sample with manufactured flaws that were used in the initial phase of our evaluations along with the listing of manufactured flaws on that sample. The scanning setup is depicted in Figure 8(b).
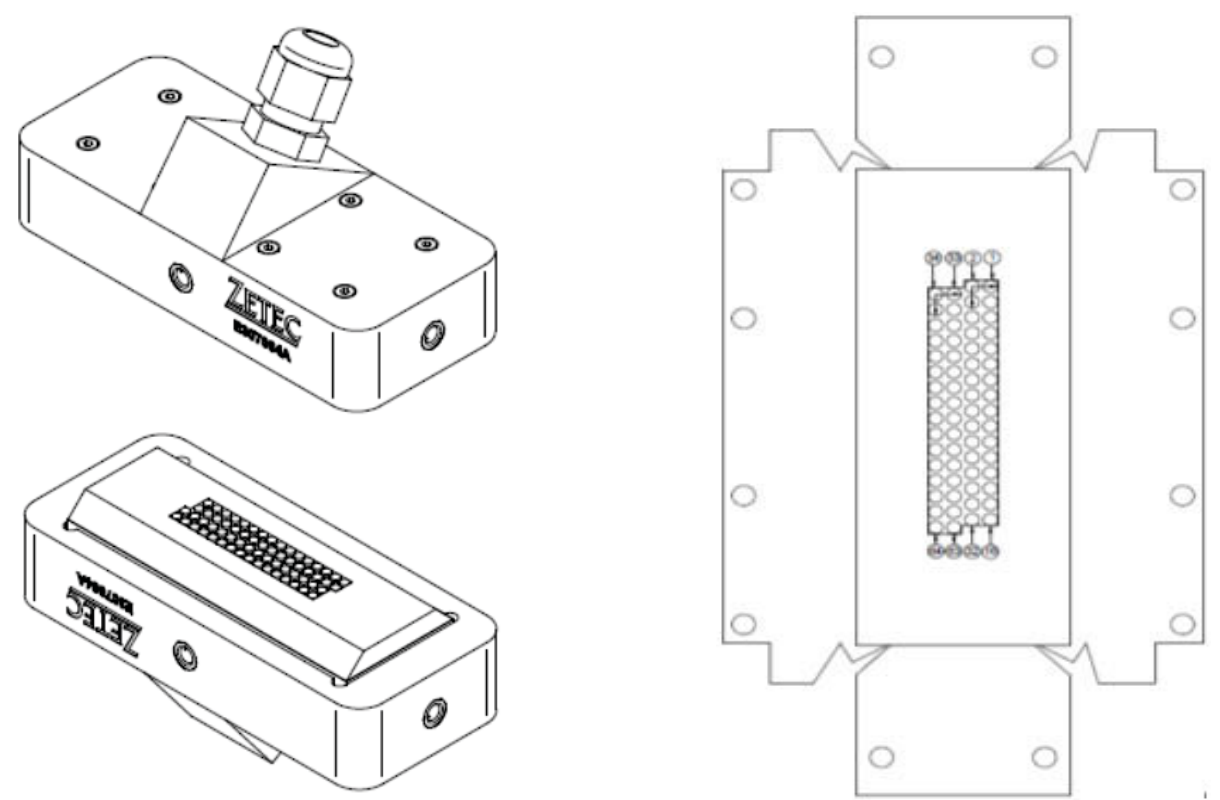

Figure 7. Array probe with 32 axial and 30 transverse elements. Shown here are the (left) top and bottom view of the probe head and (right) T-R coil configuration. Probe images provided by Zetec Inc. 


\begin{tabular}{|c|c|c|c|}
\hline \multicolumn{3}{|c|}{$\begin{array}{l}\text { Source: Sonaspection Int. (Sample PL1436, welds A \& B) } \\
\text { Material: SS304, } 0.26 \text { in. thick plate (SS308L fill) } \\
\text { Weld Process: GTAW }\end{array}$} & \\
\hline Defect Number & $\begin{array}{l}\text { Crack Length } \\
\text { (in.) }\end{array}$ & Crack Depth (in.) & \\
\hline 1 & 0.232 & 0.125 & \\
\hline 2 & 0.377 & 0.125 & \\
\hline 3 & 0.108 & 0.125 & \\
\hline 4 & 0.420 & 0.125 & \\
\hline
\end{tabular}

(a)

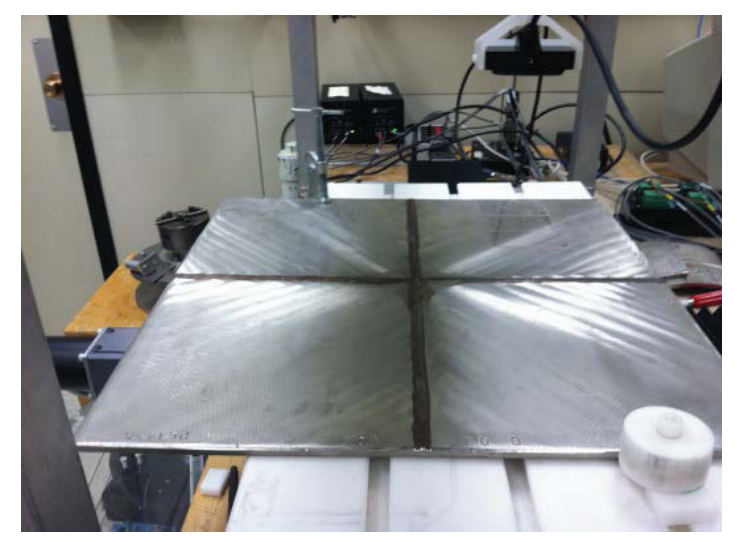

(b)

Figure 8. (a) Sonaspection plate with transverse weld cracks and tabulated data providing a list of flaws present in the sample, and (b) typical scanning setup for inspection of samples.

Eddy current inspection data collected at INL from a sample with manufactured flaws indentified as 3-toe cracks is shown in Figure 9(a). The image display, strip-chart, and impedance plots over a small region of the sample using the commercial software are shown in the main analysis window. To allow off-line processing of data using the data analysis tool developed at ANL, a series of routines were implemented to convert, calibrate, and import the data for subsequent analysis. The ANL data analysis tool is made up of various algorithms developed under the MATLAB ${ }^{\circledR}$ environment for visualization, measurement, calibration, signal processing and analysis of eddy current inspection data. The algorithms are all integrated under a common graphical user interface. Figure 9(b) displays the same data as Figure 9(a) in image and strip-chart format. The location of flaws in the processed data are marked both on vertical components of the c-scan image and along the strip-chart plot. In comparison to Figure 9(a), the results in Figure 9(b) clearly indicate significant improvement in signal-to-noise ratio $(\mathrm{S} / \mathrm{N})$ following the application of the signal processing routines available with the ANL data analysis tool. The signal here refers to the probe response from cracks and the noise refers to all other unwanted indications, including the probe response to the large discontinuity associated with the weld zone. 


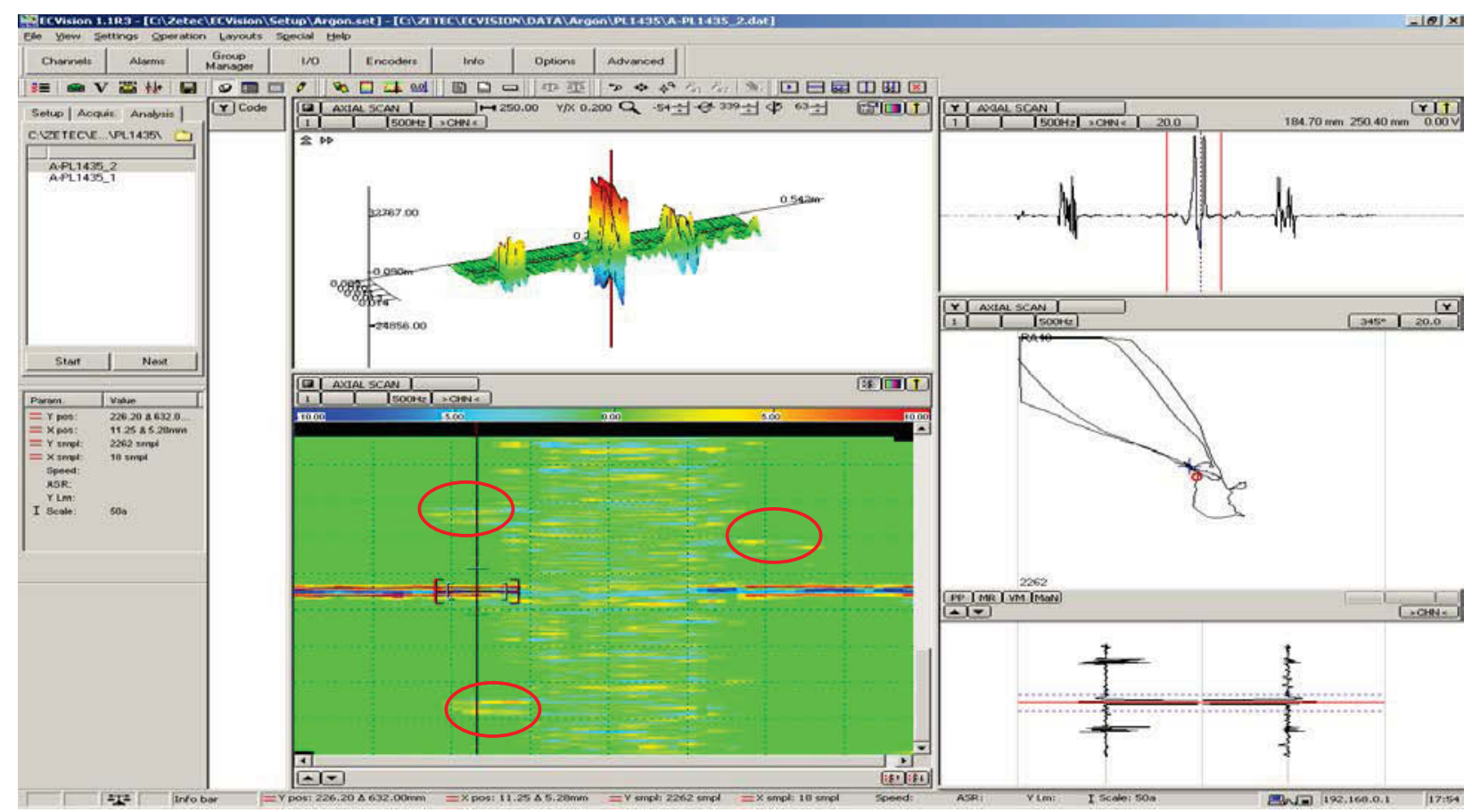

(a)
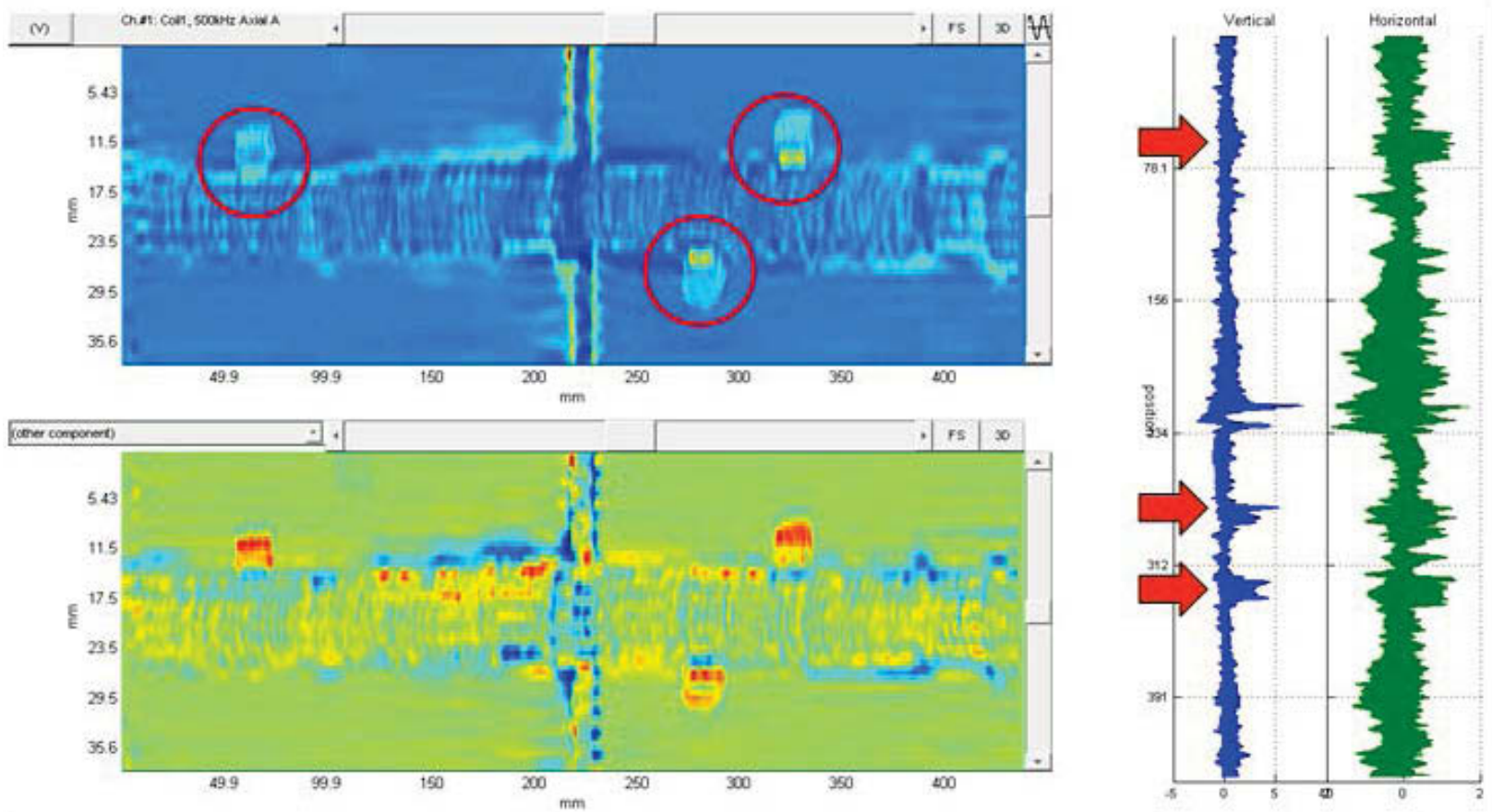

(b)

Figure 9. Eddy current inspection data collected at INL from Sonaspection plate containing 3-toe cracks: (a) shows data displayed over a small section of the sample using the commercial software and (b) shows processed data using the ANL data analysis software with the location of flaws marked by circles and arrows. 
Another example of improving the detection of flaws using modern signal processing and data analysis algorithms is shown in Figure 10. Various stages of data analysis performed on the same data at ANL are shown in Figure 10(a)-(c). Once again the processed data shows significant improvement in detection of the three flaws included in the weld sample. In reference to Figure 10, there is a clear improvement in $\mathrm{S} / \mathrm{N}$ at each subsequent stage of processing, resulting in near total elimination of the large interfering signal from the weld. The results of investigations so far suggest that the eddy current data analysis tool developed at ANL could be used to automate the detection, identification, and sizing of flaws in canister welds.

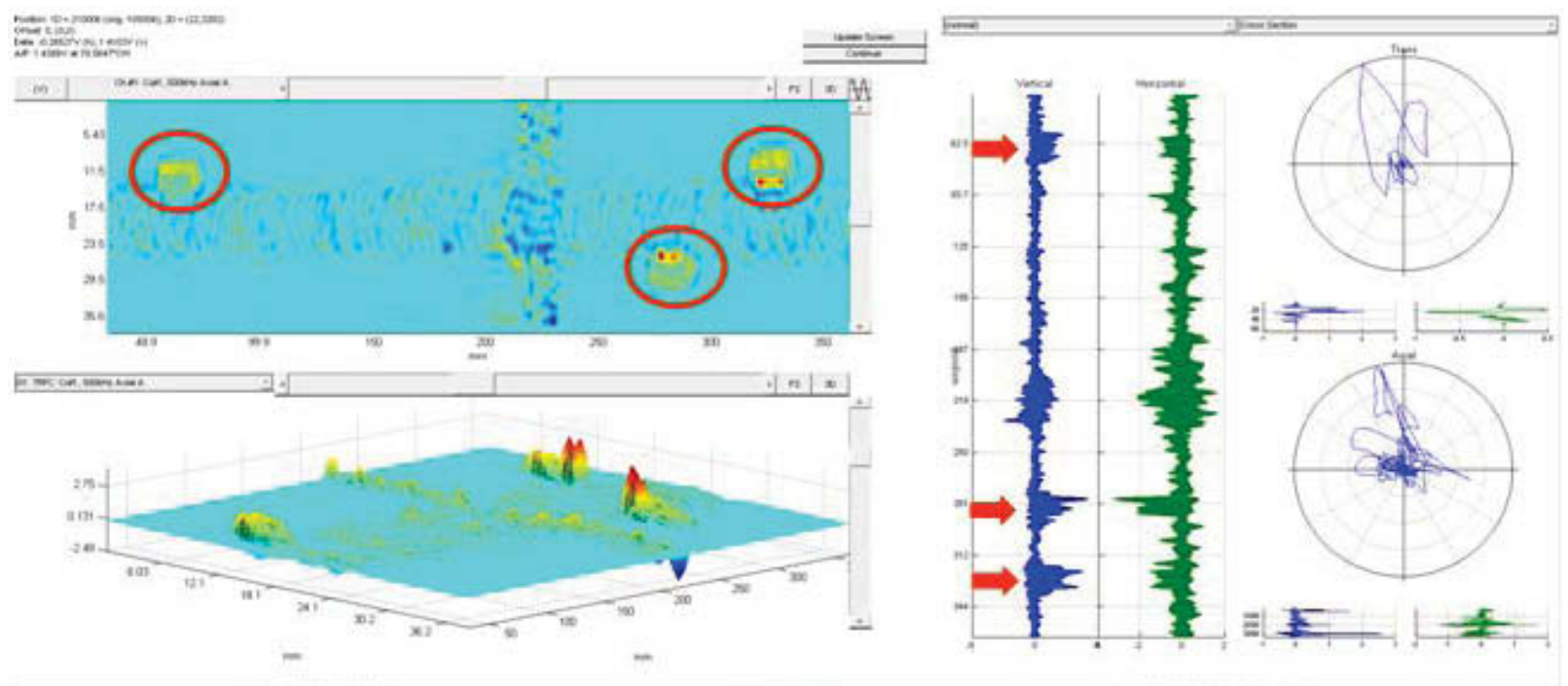

(a)

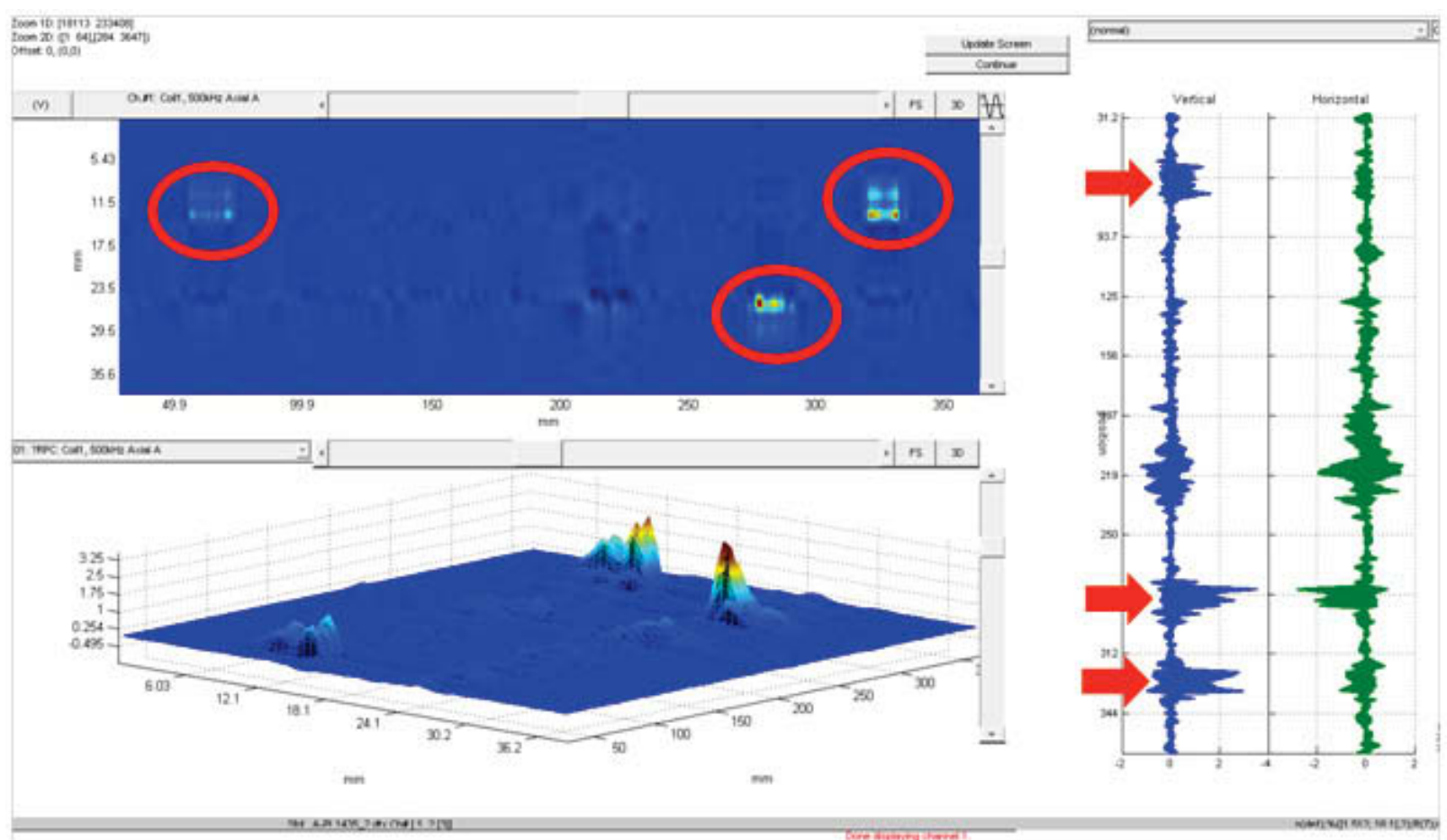

(b) 


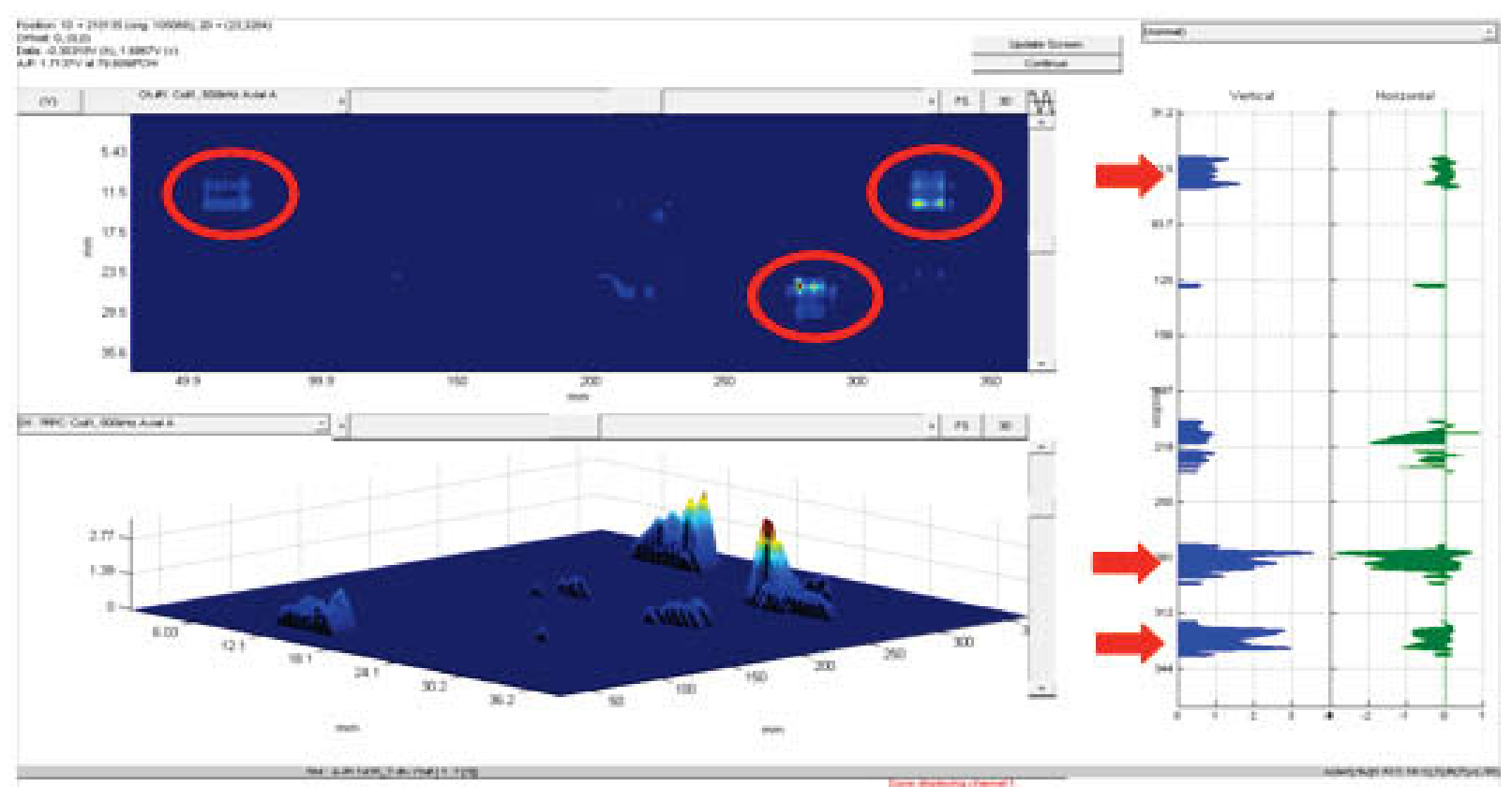

(c)

Figure 10. Eddy current inspection data collected at INL from Sonaspection plate containing 3-toe cracks shown in Figure 9(a). Data at various stages of processing are displayed using the ANL data analysis software with the location of flaws marked by circles and arrows.

Numerical simulations were also conducted to help optimize the T-R array probe design. As noted earlier, the purpose of this study was to increase the probe coverage with the same number of elements (practical manufacturing constraint) while maintaining acceptable sensitivity to the detection of limiting flaws. A hybrid 3-D numerical electromagnetic code based on volume integral formulation was used to model the eddy current probe response. Representative test cases on the variation of complex impedance as a function of changes in coil position, flaw depth, T-R coil spacing, and coil size are presented next. For the test cases shown here, the test piece was modeled as a flat plate of type 304 SS material with conductivity of $\sigma=1.45 \times 10^{6}(\mathrm{~S} / \mathrm{m})$, relative permeability of $\mu_{\mathrm{r}}=1$, and with a thickness represented by an infinite half-space. The latter assumption is valid in view of typical cask wall thickness, $\mathrm{T}$, and the operating frequency $(T>>3 \delta$, where $\delta$ is the eddy current skin depth). Unless specified otherwise, the flaw is an outer-diameter surface-breaking crack with a length of $L=12 \mathrm{~mm}(\sim 0.5 \mathrm{in}$.), a depth of $\mathrm{d}=1 \mathrm{~mm}$, and a width (opening) of $\mathrm{w}=0.05 \mathrm{~mm}$. Although the effect of frequency was has been evaluated separately, an excitation frequency of $\mathrm{f}=100 \mathrm{kHz}$ was used as the default value for all the calculations here. The nominal coil dimensions for both the transmitter and the receiver element are: inner diameter $=0.5 \mathrm{~mm}$, outer diameter $=2.0 \mathrm{~mm}$, height $=0.25 \mathrm{~mm}$, and coil spacing $=0.5 \mathrm{~mm}$ (center-tocenter spacing of $2.5 \mathrm{~mm}$ ). The coils were arbitrarily chosen to be made of 100 turns of copper wire. 
A series of tests were initially conducted to validate the numerical results. Figure 11 shows the probe response to the default crack for different probe positions. The scans represent probe motion along the coil axis and transverse to the flaw axis. To simulate typical calibrated measurements, in all cases the phase angle of the coil impedance was rotated such that the lift-off signal is nearly horizontal.

Figure 11(a) shows the impedance plot for a series of transverse scans at different locations along the flaw axis. The middle of the crack is at $0 \mathrm{~mm}$ and the end of the crack (L/2) is at $6 \mathrm{~mm}$. Figure 11(b) shows the magnitude plot of the impedance values, $|Z|$, shown in Figure 11(a) as a function of position in transverse direction. As expected, the signal amplitude drops as the probe moves toward the edge and eventually away from the crack. The composite terrain plots generated from raster scan values for the vertical and horizontal components of the impedance are shown in Figure 11(c).

Calculated probe response for various crack depths between 0.25 and $3 \mathrm{~mm}$ are shown in Figure 12 . Once again, impedance plane trajectories for five transverse scans to flaw axis along the line crossing the middle of the crack are shown in Figure 12(a). The magnitude plots $(|Z|)$ as a function of probe position along the scan direction for the same data as Figure 12(a) are shown in Figure 12(b). The results show roughly an order of magnitude change between the deepest and shallowest flaw. The calculated values also indicate the ability of the probe to detect even the shallowest flaw modeled here.

The simulated eddy current T-R probe response to a 12-mm long surface breaking crack for the coil spacings (gaps) of $0.5 \mathrm{~mm}, 1 \mathrm{~mm}$, and to $2 \mathrm{~mm}$ are shown in Figure 13. The impedance plane trajectories for transverse scans to flaw axis along the line crossing the middle of the crack are shown in Figure 13(a). The magnitude plots $(|\mathrm{Z}|)$ along the scan direction as a function of position are shown in Figure 13(b). In this particular case, the results generally display a drop by approximately a factor of 5 because of a fourfold increase in the nominal coil-to-coil spacing.

Calculated impedance values for different coil diameters, ranging from $1.5 \mathrm{~mm}$ (nominal value) to $4 \mathrm{~mm}$ are shown in Figure 14. The results in this case indicate that increasing the coil diameter up to a certain size $(\sim 3 \mathrm{~mm})$ can improve the detection sensitivity. Larger coil diameters beyond the optimum value will lead to degradation in sensitivity in conjunction with reduced spatial resolution. This is expected, as the volume fraction of the flaw within the coil field of view will be reduced for larger coil dimensions. In view of the data shown in Figures 13 and 14, the results of numerical simulations suggest that, using the same number of elements, the array probe coverage could be increased through a combination of increased coil diameter and coil spacing with the optimized design parameters dictated by the eddy current test parameters (material properties and dimensions and minimum expected flaw size, which also dictates the operating frequency). More extensive numerical simulations, however, must be conducted to determine the optimum probe design parameters to ensure acceptable detection sensitivity and spatial resolution for the wide range of test conditions that could be encountered during field examinations.

Efforts are expected to continue on the evaluation of eddy current array probe technology for rapid inspection of dry storage casks. The focus of the investigations will once again be on reliable detection and characterization of flaws at welded regions. To that end, additional numerical modeling studies will be done to best optimize the probe design. The aim in this case is to increase the probe coverage using minimum number of T-R elements while maintaining the sensitivity to detect limiting flaws. Efforts will also continue to adapt the signal processing and data analysis algorithms to the processing of data collected from representative samples. The ultimate goal is to fully automate the detection and characterization of flaws for field applications. 


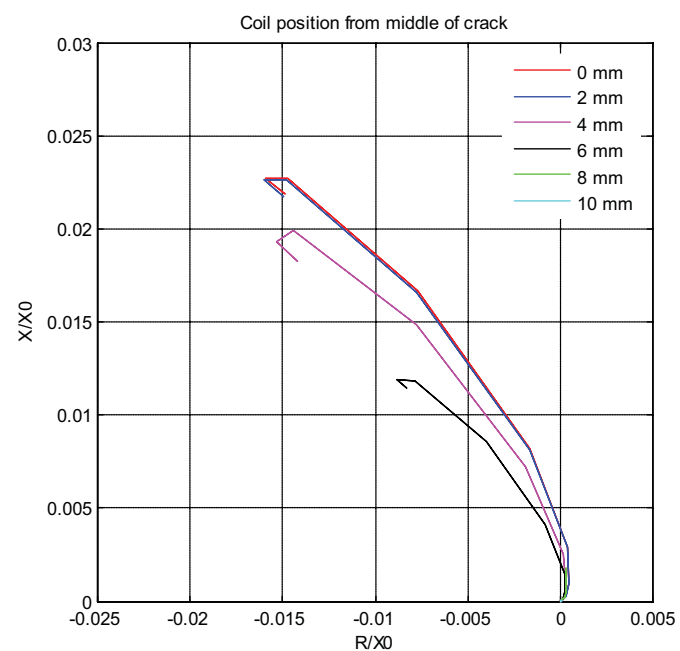

(a)

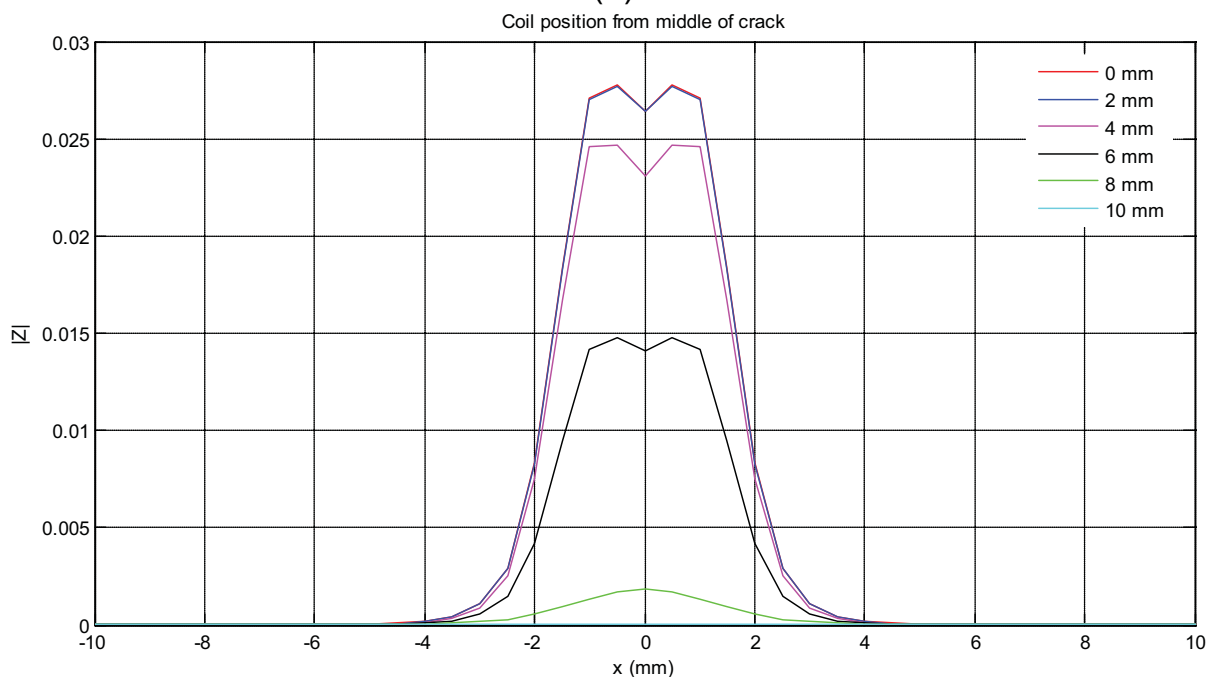

(b)
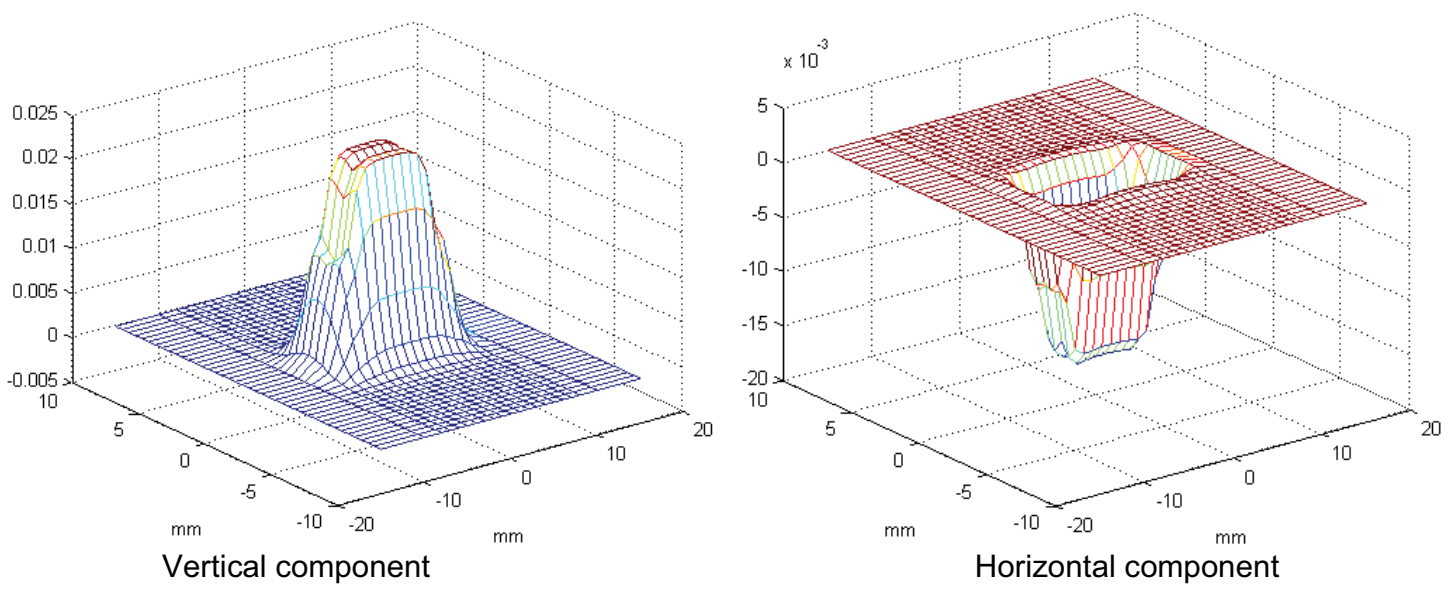

(c)

Figure 11. Simulated eddy current T-R probe response to a 12-mm long, 1-mm deep surface breaking crack in a type $304 \mathrm{SS}$ plate as a function of probe position. Figure (a) shows impedance plane trajectories for six transverse scans to flaw axis (middle of crack at $0 \mathrm{~mm}$ ), Figure (b) shows magnitude plot (|Z|) along transverse direction, and Figure (c) shows terrain plots generated from raster scan data. 


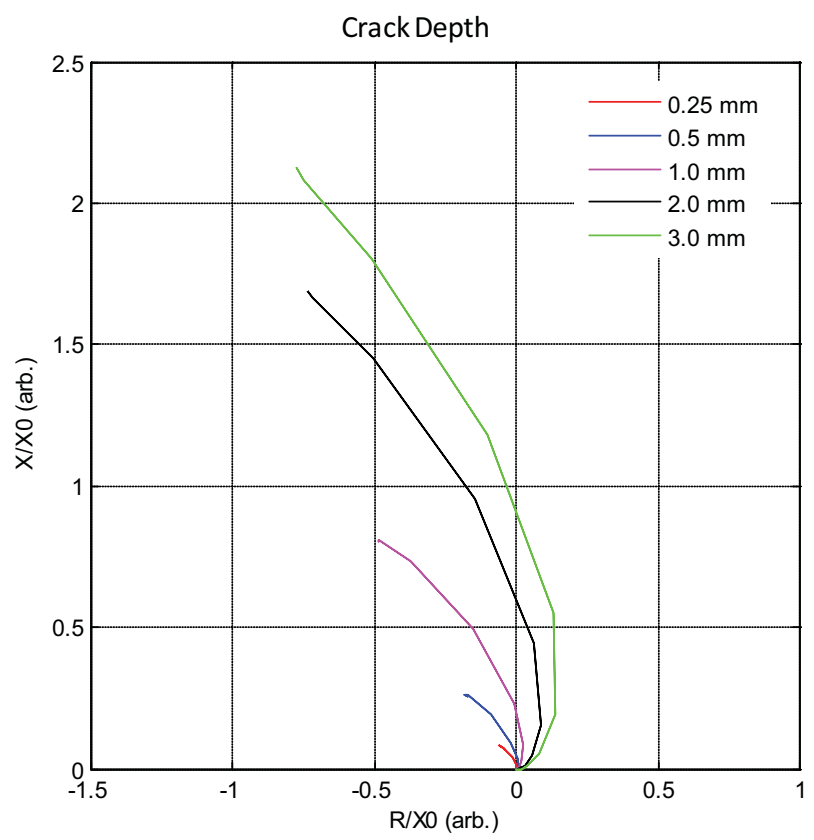

(a)

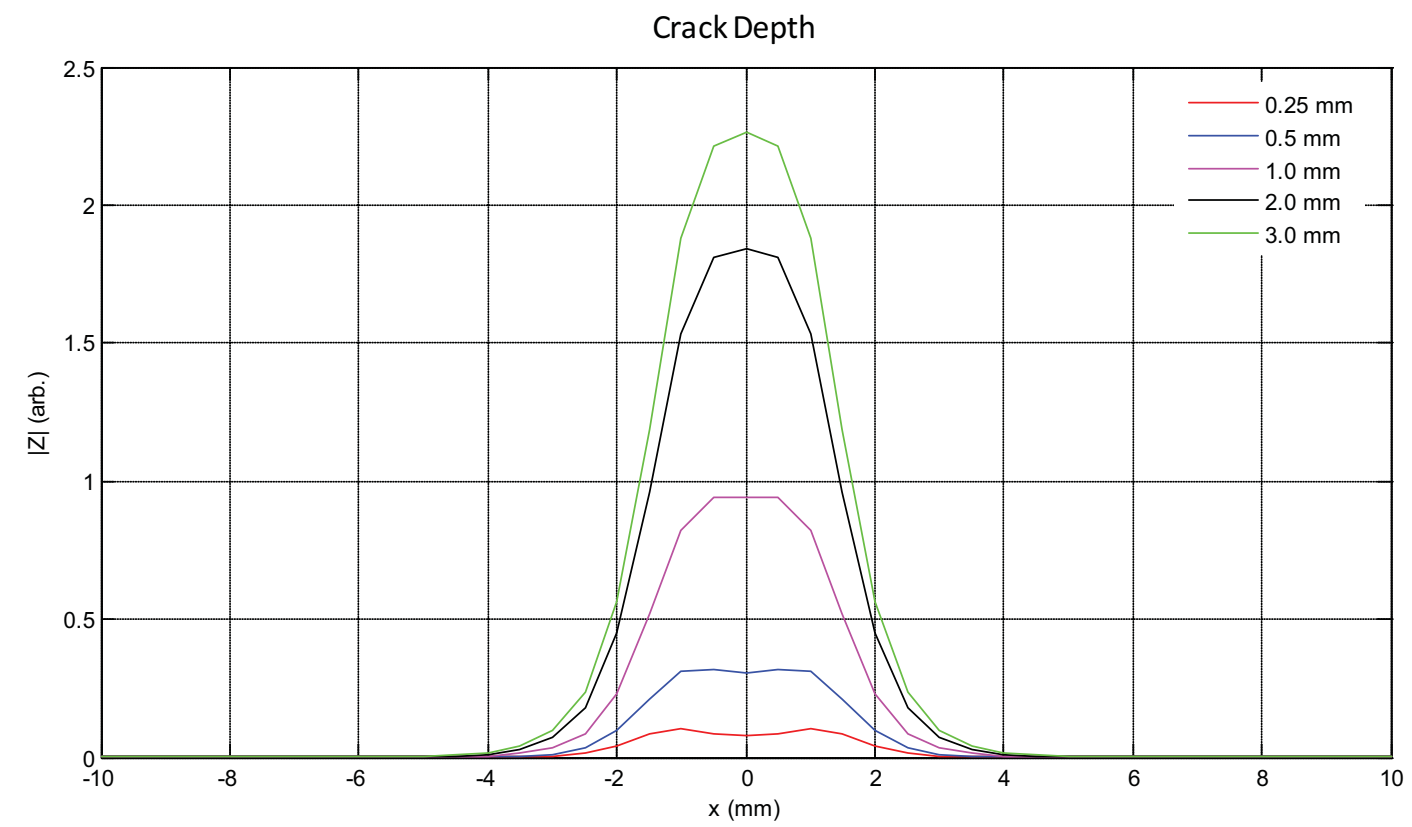

(b)

Figure 12. Simulated eddy current T-R probe response to a 12-mm long surface breaking cracks ranging from $0.25 \mathrm{~mm}$ to $3 \mathrm{~mm}$ deep in a type $304 \mathrm{SS}$ plate. Figure (a) shows impedance plane trajectories for five transverse scans to flaw axis along the line crossing the middle of the crack and Figure (b) shows magnitude plot $(|\mathrm{Z}|)$ along transverse direction as a function of position. 


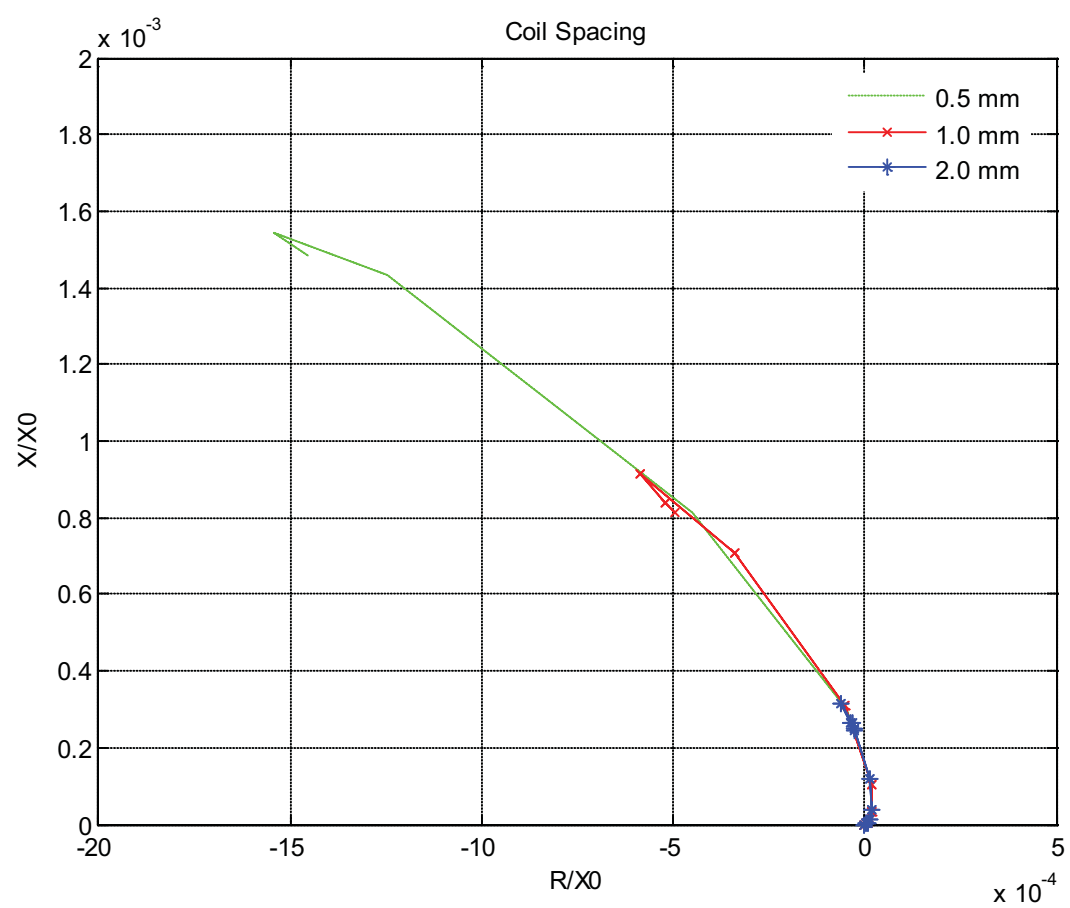

(a)

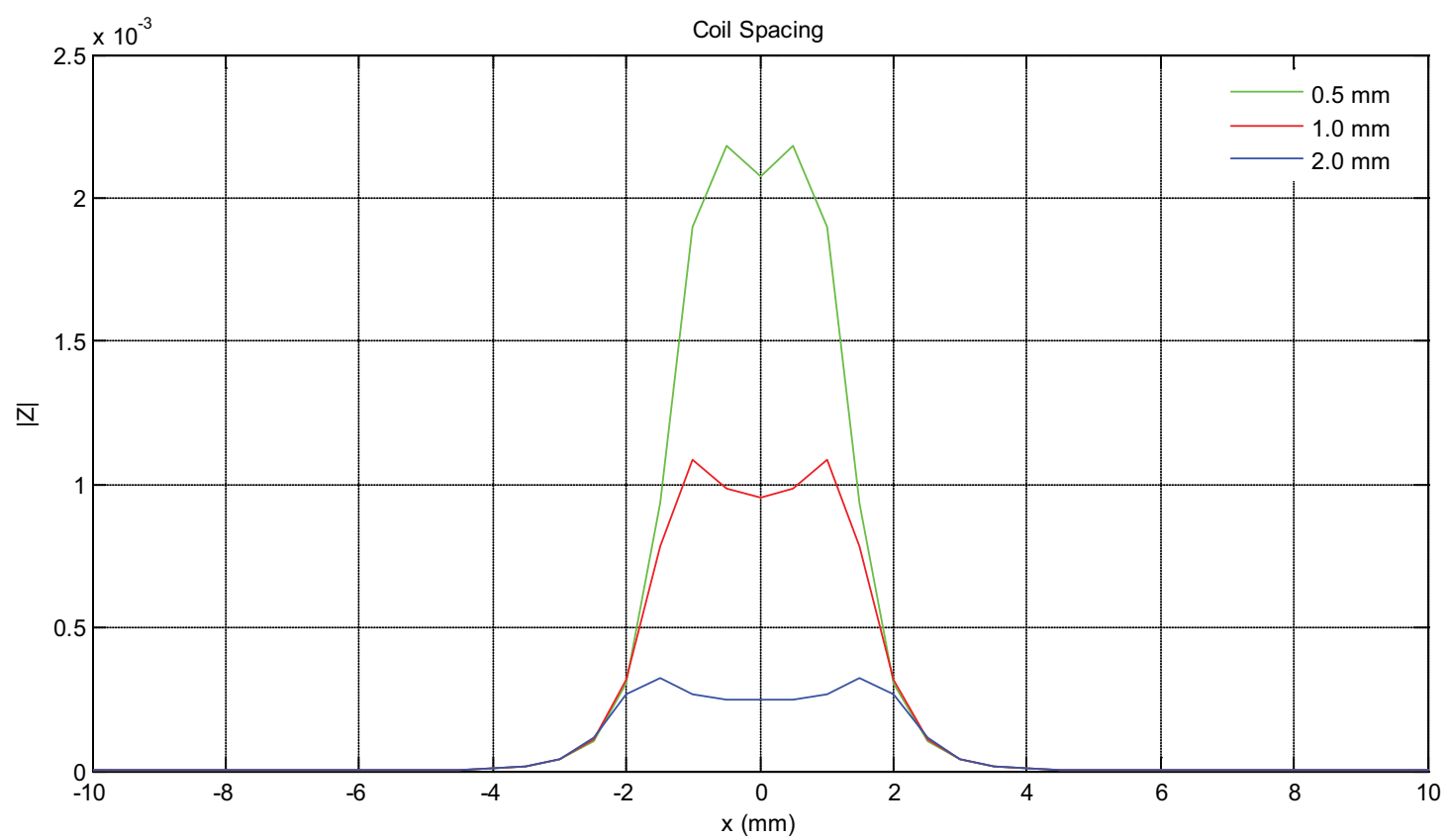

(b)

Figure 13. Simulated eddy current T-R probe response to a 12-mm long surface breaking crack in a type $304 \mathrm{SS}$ plate for three different coil spacing/gaps ranging from 0.5 to $2 \mathrm{~mm}$. Figure (a) shows impedance plane trajectories for transverse scans to flaw axis along the line crossing the middle of the crack and Figure (b) shows magnitude plot $(|\mathrm{Z}|)$ along transverse direction as a function of position. 


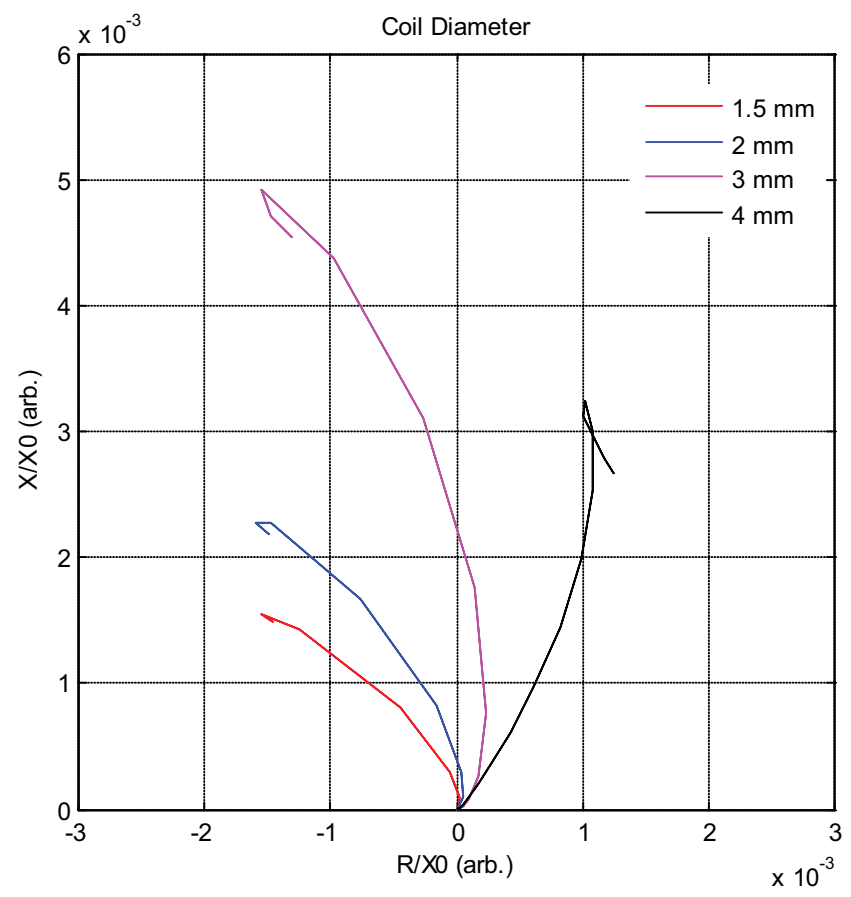

(a)

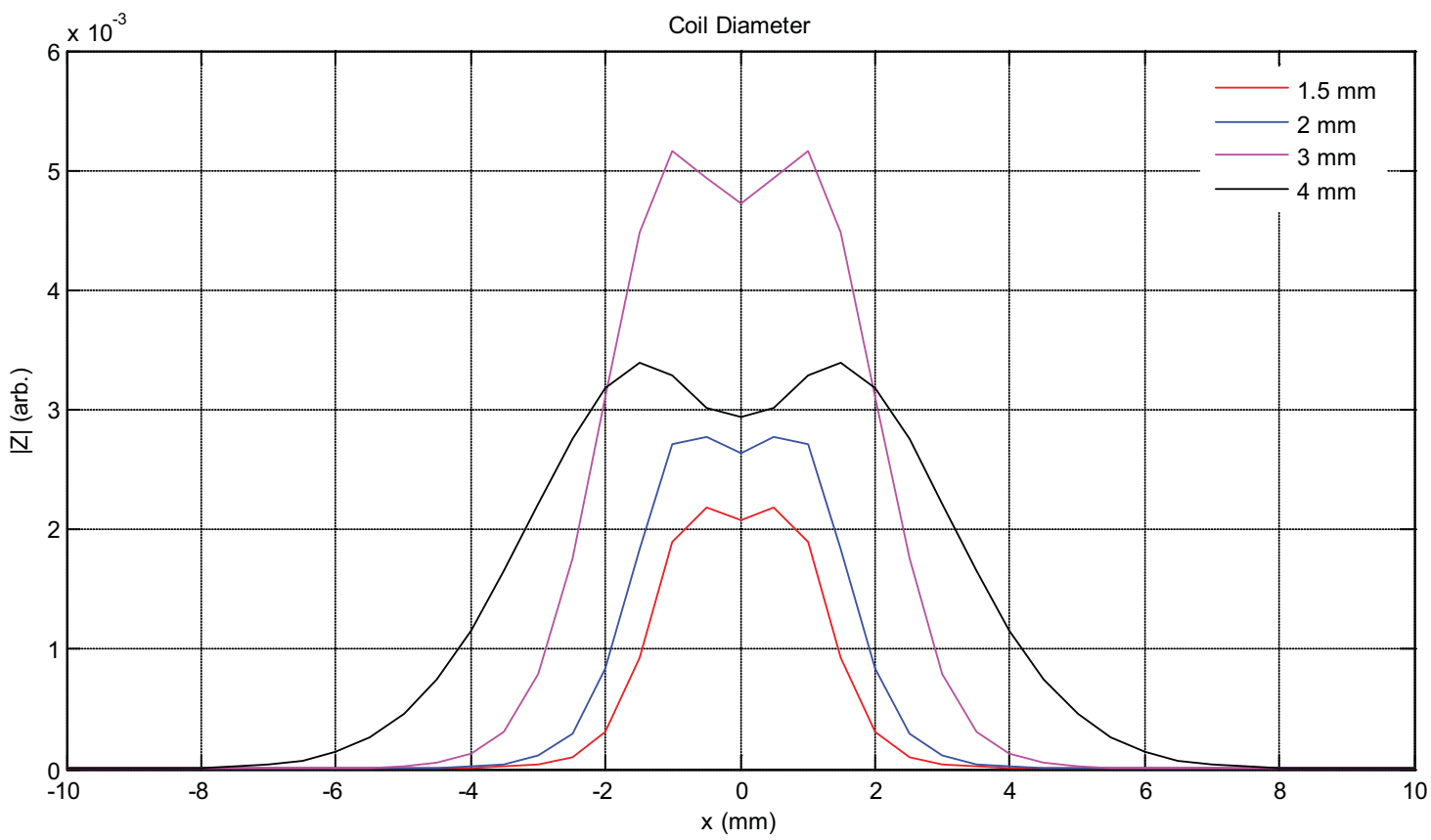

(b)

Figure 14. Simulated eddy current T-R probe response to a 12-mm long surface breaking crack in a type $304 \mathrm{SS}$ plate for four different coil diameters ranging from 1.5 to $4 \mathrm{~mm}$. Figure (a) shows impedance plane trajectories for transverse scans to flaw axis along the line crossing the middle of the crack and Figure (b) shows magnitude plot (|Z|) along transverse direction as a function of position. 
Ultrasonics testing (UT) is another inspection approach that provides volumetric characterization of material. The method uses a transducer to generate a mechanical wave that travels through the material. When a discontinuity such as a crack is met by the wave, it will reflect or diffract and possibly return to the transducer to be detected. This requires the transducer to be positioned and translated, such as by a skilled practitioner or automated UT apparatus. In the dry cask inspection application, the positioning will be necessarily remote with limited mobility, making extensive scanning and positioning difficult. A now common UT technology is phased array UT. Phased array chops a large single transducer element up into small elements, each with separate electrical connections to advanced transmitters and receivers that control the selection and timing of elements. This permits a single transducer assembly to electronically scan, focus, and steer the ultrasonic beam in a very flexible way in the proximity of the probe. Figure 15 shows mechanical and phased array methods for producing a detailed image of flaws in a component. Those methods combine to give the comprehensive details of the defects contained in a weld sample, as shown Figure 16. However, as stated, an extended mechanical scan range is not practical for a loaded storage cask but localized volumetric scanning may be accomplished with a 2-D phased array probe. The probe must be designed to be carried on the same or similar apparatus as the visual and surface inspection probes and would be placed in an area of interest using water as the couplant of ultrasound from the probe to the surface of the part. Couplant water would need to be supplied to the transducer in the same umbilical cord containing the signal wires. Scanning in 3-D is possible with the 2-D array, allowing the maximum volume from numerous angles and focus depths to be achieved.
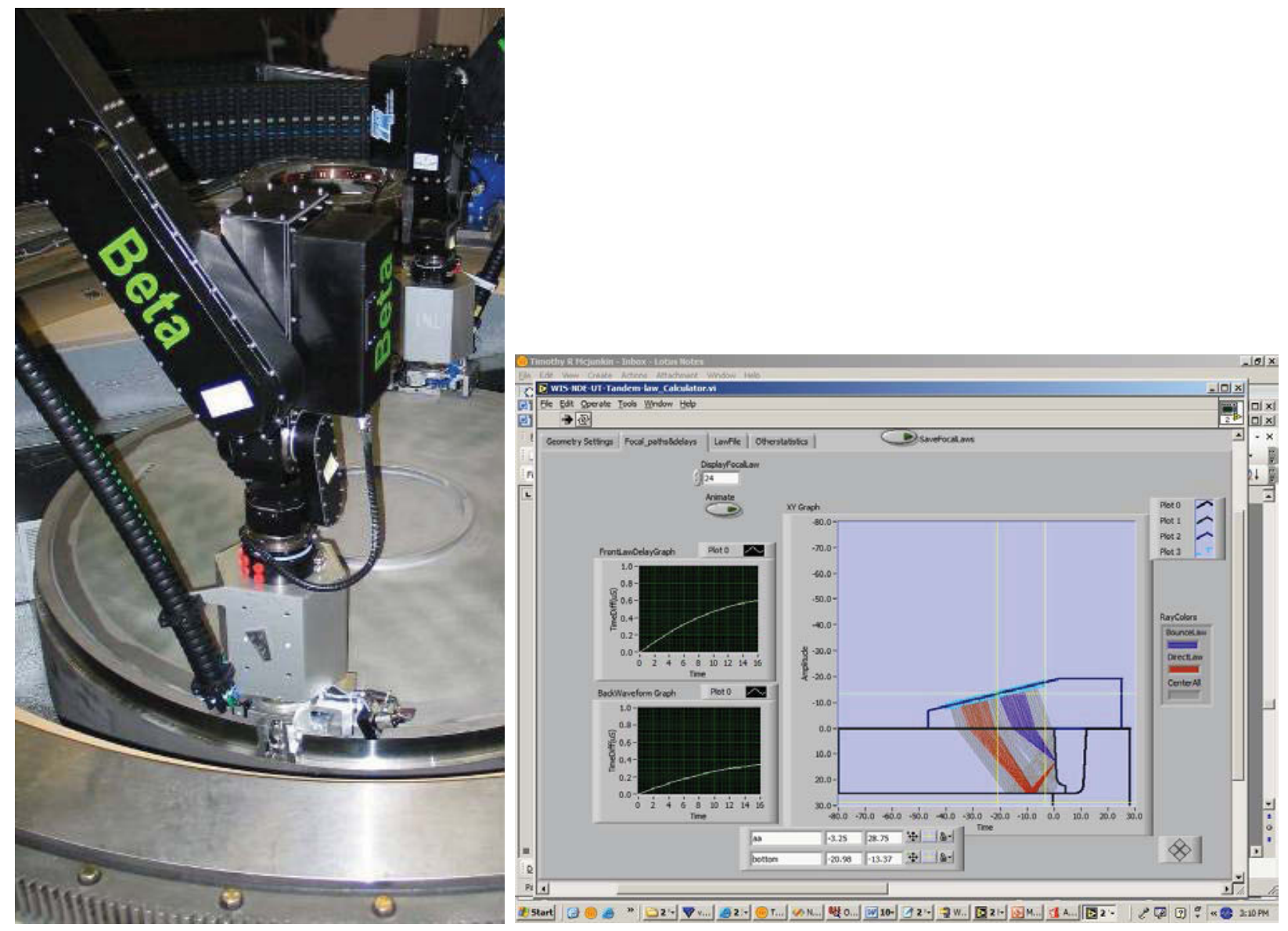

Figure 15. Two methods of scanning material: (left) an articulated positioning system for scanning a canister, (right) the electronic scanning and focusing available through phased array ultrasonics. 


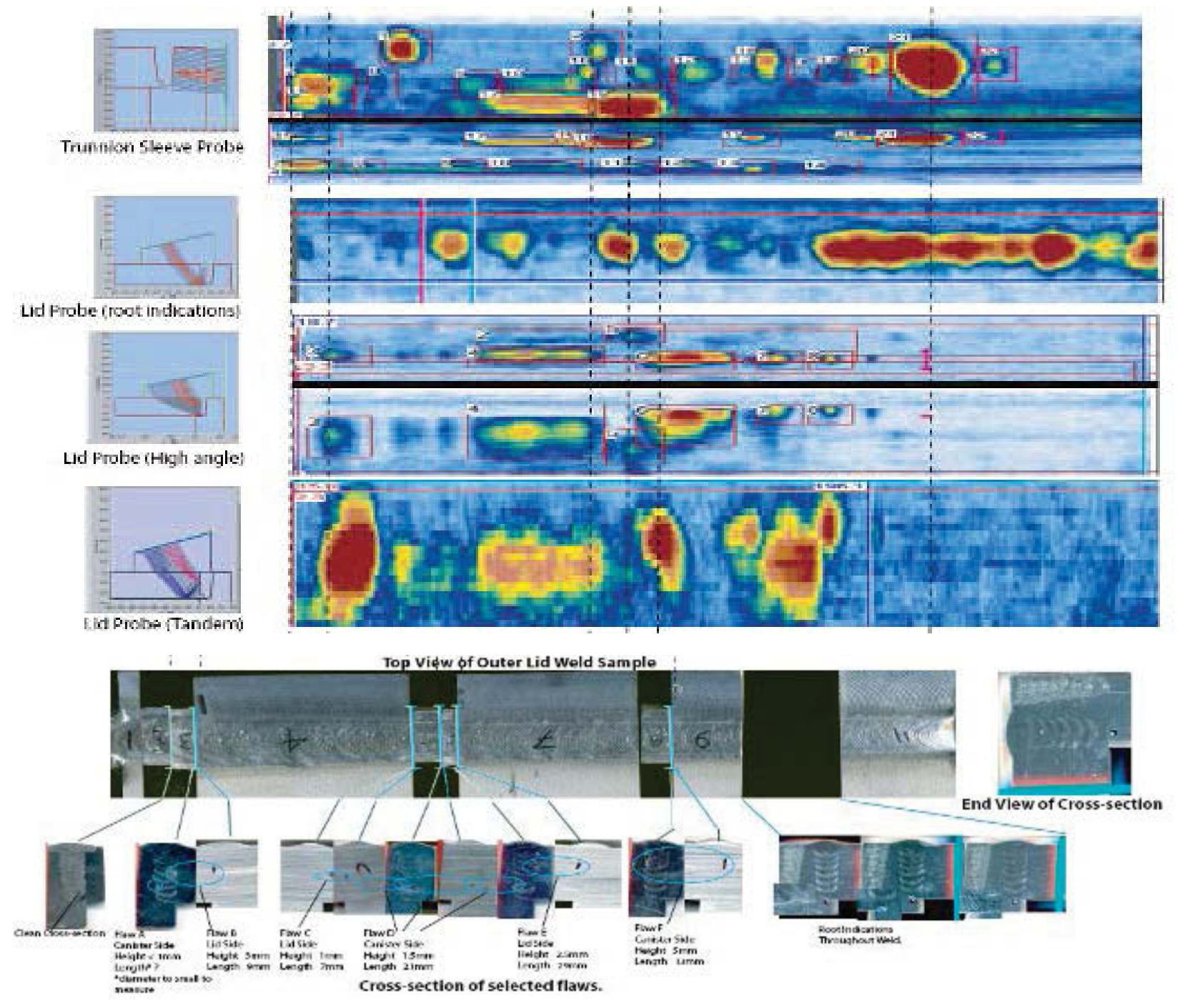

Figure 16. Combining mechanical scanning with phased array scanning and focusing produces a detailed view of the material defects as shown in the UT volumetric data shown with the cross-sections of the weld that was scanned.

Since limited positioning and scanning is assumed, the accumulation of all of the data volume available at that spot may be crucial. The method of Total Matrix developed by C. Holmes ${ }^{4}$ provides a method for collection of all possible array combinations by firing elements of the transducer individually and collecting response from each of the individual elements. In post processing any combination of focal delays may be applied to the data set. Although taking significantly greater time to acquire, a comprehensive field of data for that probe position is obtained that may be exploited for any arbitrary location in the volume near the probe location. Another relatively slow adaptive method presently being evaluated by T. Mcjunkin ${ }^{5}$ may also be viable where any returned signal can be interrogated in detail by auto focusing on signals and analyzing the focusing delays to determine the exact location of the reflection, as shown in Figure 17. Given slow of no scanning of the probe for the dry storage cask, these detailed interrogations of local areas of interest are possibly viable options. 


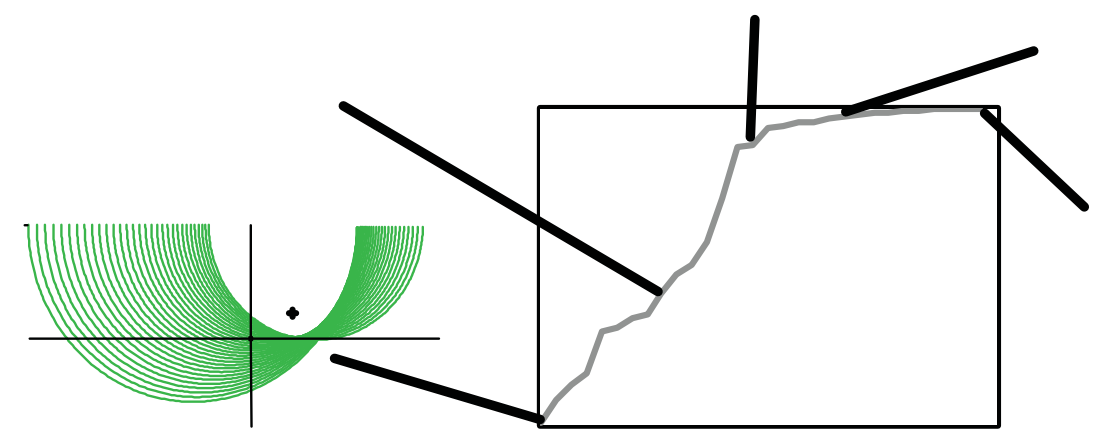

Figure 17. Auto focusing and analysis of the focal delays allows the determination of the exact physical location of the reflection. The amplitude over the period of focusing is shown in the center along with the expected location of Shear and Longitudinal wave fronts. Convergence of the L-wave on the bottom right establishes the location of a reflection with respect to the transducer.

Future efforts will continue to evaluate and test the eddy current and ultrasonic inspection approaches described above on environmental conditions, materials, and geometries typical for used fuel dry storage casks. Those test parameters include 300 series stainless steel construction, cylindrical geometry, elevated surface temperatures, weld/weld crown geometries and the possible presence of accumulated debris on the test surface.

\section{SUMMARY}

Visual, eddy current, and ultrasonic inspection technologies are well established with demonstrated capabilities to detect and characterize various forms of material degradation including corrosion and cracking. They have been successfully applied to materials at elevated temperatures and in radiation environments and therefore have the potential to provide details regarding the integrity of used fuel dry storage casks. The efforts described above are based on adapting existing inspection technologies, array eddy currents, and phased array ultrasonics to existing dry storage configurations that have limited access to the storage casks. This imposes significant limitations on positioning and translating transducers. For this reason, the work being performed targets approaches that emphasize the use of transducers with reduced sizes and capabilities that can provide information with little or no mechanical scanning.

The path forward is to:

1. Use modeling and/or laboratory experimentation to determine the configuration/design for prototype eddy current and ultrasonic sensors that can be used to characterize basic inspection capabilities and demonstrate feasibility in the laboratory. The design will include considerations for deployment and test environments.

2. Work with NDE vendors to obtain prototype sensors. Obtain or fabricate test samples.

3. Perform a laboratory evaluation of prototype sensors to characterize capabilities, demonstrate feasibility, and test methods of deployment. Identify deficiencies in the prototype or intended methods of deployment and modify the design and deployment approach as required to address the 
deficiencies. Test modifications to determine viability. Iterate previous steps as required to obtain functional inspection capabilities. A parallel effort will be to develop data acquisition and analysis methods for the prototype systems.

4. Build a field deployable prototype based on final laboratory designs. Identify the collaborators and a test location for a field test of the inspection system(s).

5. Perform a field test to determine capabilities and demonstrate feasibility.

6. Transfer the inspection technology to industry.

An alternative to working in the constrained environment described above is the option of building an overpack structure for temporary use specifically designed for cask inspection purposes. The design of the overpack may be as simple as being oversized to allow easier access by external robotic deployment systems or more sophisticated with integrated scanning and probe manipulation hardware designed to place and scan a variety conventional inspection probes. The advantage of this approach is that existing inspection hardware can be implemented without the need to develop reduced size probes and complex deployment systems that have limited capabilities regarding coverage and data collection. This approach would significantly increase inspection capabilities and provide increased confidence in determining cask integrity.

\section{REFERENCES}

1. "Gap Analysis to Support Extended Storage of Used Nuclear Fuel," FCRD-Used-2011-000136, Rev. 0, PNNL-20509, January 31, 2012.

2. "Used Nuclear Fuel Storage and Transportation Data Gap Prioritization," FCRD-Used-2012-000109, PNNL-21360, April 30, 2012.

3. "Managing Aging Effects on Dry Cask Storage Systems for Extended Long-Term Storage and Transportation of Used Fuel,” FCRD-Used-2012-000119, ANL-12/29, June 30, 2012.

4. C. Holmes, B. W. Drinkwater, and P. D. Wilcox, "Advanced post-processing for scanned ultrasonic arrays: Application to defect detection and classification in non-destructive evaluation," Ultrasonics, Vol. 48, No. 6-7, pp. 636-642, 2008, selected Papers from ICU 2007.

5. T. R. McJunkin and M. Manic, "Evolutionary adaptive discovery of phased array sensor signal identification," Human System Interactions (HSI), 2011 4th International Conference) May 2011, pp. 229 \{236. [Online]. Available: http://dx.doi.org/10.1109/HSI.2011.5937371\}. 